\title{
Quantifying and modelling the ENSO phenomenon and extreme discharge events relation in the La Plata Basin
}

\section{Melanie Meis , María Paula Llano \& Daniela Rodriguez}

To cite this article: Melanie Meis , María Paula Llano \& Daniela Rodriguez (2020): Quantifying and modelling the ENSO phenomenon and extreme discharge events relation in the La Plata Basin, Hydrological Sciences Journal, DOI: 10.1080/02626667.2020.1843655

To link to this article: https://doi.org/10.1080/02626667.2020.1843655

曲

Accepted author version posted online: 28 Oct 2020.

Submit your article to this journal $\sqrt{3}$

แII Article views: 2

a)

View related articles $\sqsubset$

View Crossmark data $־$ 
Publisher: Taylor \& Francis \& IAHS

Journal: Hydrological Sciences Journal

DOI: $10.1080 / 02626667.2020 .1843655$

\title{
Quantifying and modelling the ENSO phenomenon and extreme discharge
} events relation in the La Plata Basin

\author{
Melanie Meis ${ }^{1,2, *}$, María Paula Llano ${ }^{1,2}$, Daniela Rodriguez ${ }^{2,3}$ \\ ${ }^{1}$ Departamento de Ciencias de la Atmósfera y los Océanos (FCEN-UBA) \\ ${ }^{2}$ Consejo Nacional de Investigaciones Científicas y Tecnológicas (CONICET) \\ ${ }^{3}$ Instituto del Calculo (IC-UBA-CONICET))
}

Intendente Güiraldes 2160, Ciudad Universitaria, Pab 2 (C1428EGA), Buenos Aires, Argentina. *mmeis@at.fcen.uba.ar

\begin{abstract}
Understanding and monitoring extreme events is essential, particularly in river discharges from the La Plata Basin, which concentrates a large percentage of the economic resources and population of the region. In this article, we seek to quantify the relationship between extreme events in discharge and the seasonal climatic index NIÑO 3.4. We start by estimating the phase shift between the index and mean seasonal (trimester) discharge values. Based on this result, we align the series and use the copula method to fit a joint distribution. We end up with a model that is particularly useful for quantifying the probability of occurrence of extreme events and monitoring their return periods. As a final step, we generate predictions and validate the model
\end{abstract}


by splitting the series into training and test datasets. We develop a simple effective model for monitoring discharges using the ENSO index.

Keywords: La Plata Basin; Extreme Events; Monitoring; ENSO; Joint Probability; Return Period; Validation

\section{Introduction}

Studying extreme precipitation and streamflow events in the La Plata Basin (LPB) is essential. These events have adverse effects ranging from economic losses for different social groups, to possible disease outbreaks, navigation problems, among others. Flood risk is a crucial hydrological variable in terms of social and economic importance (Kiem et al., 2003). In this sense, Re and Barros (2009) studied extreme precipitation events in the southeast region of South America during the latter half of the twentieth century and found a positive trend in the annual maximum precipitation values, as well as an increased frequency of extreme events. The increased incidence of extreme events in the south region of the LPB has also been pointed out in Cavalcanti et al. (2015).

Other studies have established a relation between extreme streamflow events and the ENSO phenomenon in the LPB. Camilloni and Barros (2000) analyzed this relation from convection in the higher and mid Paraná River, and the sea level temperature (SST) in the NIÑO-1+2 and NIÑO-3 regions. Additionally, Camilloni and Barros (2003) noticed a clear relation between the ENSO phases and the discharge anomalies in the higher Paraná. Besides, Berri et al. (2002) studied the connection between mean discharge and ENSO events for the upper Paraná River, showing evidence of increased mean streamflow during El Niño events. On 
the other hand, most great floods which occurred in the LPB region related to the El Niño events. In this sense, Antico et al. (2015) analyzed the relation between the contribution that different oscillations had on the four most significant floods registered in the Paraná River.

The streamflow-ENSO correlation can be studied using hydrological stochastic models. Many authors have used multivariate stochastic models to study the relationship between several meteorological and hydrological variables in different regions of the world. AghaKouchak et al. (2014) quantified the joint risk of abnormal temperature and precipitation in certain gauging stations in California, United States, intending to help decision-makers. Khendun et al. (2014) modeled the relation between PDO, ENSO, and precipitation anomalies in the state of Texas and defined a prediction model for extreme events. Cong and Brandy (2012) estimated the relation between precipitation and temperature in a region in Sweden using a copula model. Their final objective was informing agricultural policy decision-makers in the context of climate change.

Fang et al. (2018) used copula models to analyze the relation between the standardized precipitation index of adjacent dry and wet seasons. Additionally, Ganguli and Reddy (2013) analyzed the relation between ENSO and drought risk in a region in India. The results suggest that including ENSO in the climatic variability copula model is useful for risk drought studies and the management of water resources in the area. In this sense, Ward et al. (2014) have shown, on a global scale, that ENSO exerts strong and widespread influences in both hazard and risk flood. Moreover, the authors highlighted that true anomaly of flood risk exists during El Niño or La Niña years, or both.

As exposed, there is a strong relation between ENSO phenomenon and flood hazard in many parts of the world. Therefore, any effort that we could do in terms of quantifying this relationship is of interest. In that sense, this work aims to study extreme discharge events in the 
Paraná and Uruguay Rivers regarding the ENSO phenomena, using stochastic methodologies, such as the copula method. This methodology has many advantages over the classical methods considered in the study of climate and hydrology. Most of the existing stochastic approaches to this problem assume a linear relationship between the variables, while copula methodology has the capability of capturing nonlinear structures in the dependence variables (Zhang and Singh, 2012; AghaKouchak et al., 2010). Moreover, we are obtaining an estimate of the bivariate density, which is a core metric for the relationship between the random variables. Knowing an estimate of the density allows us to derive a wide variety of results, ranging from very simple ones such as correlations or return periods to more complex ones, such as conditional expectations given observed values. We estimate the occurrence of extreme streamflow events and their relationship with ENSO events using a probabilistic model, considering the last variable shifted. Moreover, we find ways to quantify this relation and generate forecasts. This approach might help inform policy decision-makers in the LPB region, particularly when managing water resources in the area, since the LPB is a critical water and energy source for the countries in the basin (Popescu et al, 2014). The importance of quantifying and understanding hydrological variability is exposed through the literature, for example in Kiem et al. (2013).

\section{Data and Methodology}

Through this work, we used data of mean monthly streamflow $\left(\mathrm{m}^{3} / \mathrm{s}\right)$ in two different gauging stations: Túnel Subfluvial (Paraná River) and Paso de los Libres (Uruguay River), Figure 1, Table I. We obtained this data from the Subsecretaría de Recursos Hídricos (Argentine Undersecretariat for Water Resource, SRH). We analyzed 44 years for both gauging stations: December 1974 to November 2016 for Túnel Subfluvial, and December 1974 to December 2015 
for Paso de los Libres. Also, we considered the ENSO climatic index for the same period as Túnel Subfluvial data. ${ }^{1}$ We based the decision to analyze a period starting in 1974 in there being evidence of a significant change in the circulation regime in the Southern Hemisphere (García and Vargas, 1998).

We divided the time series by season, and employed seasonal discharge means (Dec-JanFeb, Mar-Apr-May, Jun-Jul-Aug, and Sep-Oct-Nov). Figure 2 shows the evolution of the seasonal (trimester) time series in the study period for the Túnel Subfluvial and Paso de los Libres streamflow, and the NIÑO 3.4 index. Moreover, we used the Augmented Dickey-Fuller test (1996) and Phillips-Perron test (1998) to analyze the stationarity condition in the time series with a $5 \%$ significance. Both tests have the same null hypothesis, that the time series presents a unit root in its characteristic equation and therefore is not stationary. The alternative hypothesis depends on the version of the test, in this case it is that the series is stationary. The main difference between both methods lies in how the distribution of the statistic under the null hypothesis is obtained. Finally, it is essential to say that testing for stationarity is necessary as most of the statistical methods we employed rely on it.

For both gauging stations, we analyzed the same period of the time series of streamflow and NIÑO 3.4. We started our analysis exploring the relation between Túnel Subfluvial-NIÑO 3.4, and Paso de los Libres-NIÑO 3.4 by using the cross-correlation function of each pair. In both cases, we computed the Spearman correlation (Siegel, 1985) between streamflow and index series, applying the lag which presented the highest correlation value.

\footnotetext{
${ }^{1}$ https://www.esrl.noaa.gov/psd/gcos_wgsp/Timeseries/Nino34/
} 
Afterwards, intending to assess the presence of significant waves in the time series considered, we employed the cross-wavelet and wavelet coherence methodologies (Maraun and Kurths, 2004; Grinsted et al., 2004).

The cross-wavelet transform spectrum can be defined as:

$$
W_{n}^{x y}(s)=W_{n}^{x}(s) W_{n}^{y *}(s)
$$

where $x, y$ are the two-time series; $W_{n}^{x}(s), W_{n}^{y}(s)$ are the wavelet transforms, and $W_{n}^{y *}(s)$ indicates a complex conjugate (Torrence and Compo, 1998). As the cross wavelet spectrum is complex, the cross-wavelet power is defined as:

$$
\left|W_{n}^{x y}(s)\right|
$$

Additionally, from this transform, we can compute cross-wavelet coherence for two given series, which is a powerful tool for detecting common waves in two series that occur in a particular time frame, given a pre-established significance level. Another useful measure for this analysis is the cross-wavelet phase, which is useful for estimating phase shifts in the abovementioned common waves. For this study, we followed the procedure in Grinsted et al. (2004). We applied this method to estimate the phase shift between the series studied in this work.

Since quantifying multivariate relations in extreme events was one of the aims in this work, we estimated multivariate probabilistic functions using the copula methodology. Following Sklar theorem (1959), if $F_{X Y}$ is the joint distribution function of a pair of random variables $(x, y)$ with $F_{x}$ and $F_{Y}$ marginal distributions, there is a unique 2-copula function such that

$$
F(x, y)_{X, Y}=C\left(F_{X}(x), F_{Y}(y)\right)
$$


For all $x, y \in R$. If $F_{X}$ and $F_{Y}$ are continuous functions, there is a unique $\mathrm{C}$; otherwise, $\mathrm{C}$ is defined only in the $F_{X} \times F_{Y}$ range.

Alternatively, if $\mathrm{C}$ is a 2-copula, and $F_{X}$ and $F_{Y}$ are distribution functions, the $F_{X Y}$, the function given by Eq.3 is a joint distribution function with $F_{X}$ and $F_{Y}$ marginal distributions.

To estimate joint probability distributions through the copula theory, we needed to obtain the marginal distribution fit for each time series first. Thus, we employed the maximum likelihood method for identifying parameters and distribution of each gauging station and index, among different classical distribution functions (Normal, Lognormal, Gamma, Gumbel, Weibull). Additionally, we analyzed the corresponding goodness of fit using the KolmogorovSmirnov test through Bootstrap resampling with 95\% confidence (Meis and Llano, 2019).

). We should mention that whenever more than one theoretical distribution did not reject the null hypothesis; we chose the one with the lower AIC (Akaike Criterion).

Using the theoretical marginal distributions that provided the best fit, we proceeded to select the copula function that best described the bivariate relation between each streamflowindex pair by using the algorithm proposed by Schepsmeier et al. (2018). In this sense, we ended up choosing a copula among different families (according to the AIC criterion), obtaining an estimated joint probability distribution function in each case. We performed a goodness of fit for the copula family using Bootstrap resampling with 95\% confidence (Schepsmeier et al., 2018), considering the Cramer-Von Mises (CVM) and Kolmogorov-Smirnov (KS) tests.

In order to evaluate the models, we split the time series into 70/30 training and test sets. We fitted the copula model in the training set and then assessed the goodness-of-fit of the calibrated model in both training and test sets. As our methodology describes, we always used 
Cramer-Von Mises (CVM) and Kolmogorov-Smirnov (KS) tests for goodness-of-fit. We repeated this procedure using two different methods for the 70/30 split. In the first method, following Khendun et al. (2014) we split the series randomly. In the second method, we split the series temporally to replicate a forecast situation, taking the first $70 \%$ of the series as training data and keeping the remaining $30 \%$ for testing.

Once we fitted a copula to our data, and after performing model validation as well as obtaining the corresponding joint distribution of streamflow and index for each station, we used the model for forecasting. The approach we proposed is sampling predicted values for the response variable from the conditional distribution obtained after observing a value for the explanatory one, and then computing metrics of interest, such as conditional expectation or quantiles, which we used for forecasting.

We first explain our methodology for getting a sample from the dependent variable $Y$ (discharge) given an observation $X=x$ (index) and the copula model estimate of the joint distribution. It consists on the following steps:

1. Transformed $X$ and $Y$ to uniform variables by applying the inverse of their cumulative distribution function. Obtained $U_{1}=F_{X}^{-1}(X)$ and $U_{2}=F_{Y}^{-1}(Y)$ uniform variables and named $u_{1}=F_{X}^{-1}(x)$ the observed value from $U_{1}$ corresponding to $x$, the observed value from $X$.

2. Obtained a conditional sample $u_{2}$ from $U_{2}$ given $U_{1}=u_{1}$ using the conditional function distribution from the copula (Eq. 4).

3. Transformed the uniform sample $u_{2}$ to the space of the original variable $Y$ applying $F_{Y}$, thus obtaining a sampled value $y=F_{Y}\left(u_{2}\right)$. 
We carried out this procedure using the implementation proposed by Schepsmeier et al. (2018).

$$
C_{2}\left(u_{2} \mid u_{1}\right)=P\left(U_{2} \leq u_{2} \mid U_{1}=u_{1}\right)=\frac{\partial^{1} C\left(u_{1}, u_{2}\right)}{\partial u_{1}}
$$

Once equipped with the ability to sample values of $Y$ from observations of $X$ we took two different approaches for forecasting. Initially, we estimated the expected value of $Y$ given an observation of $X$ and compared it to the corresponding observed value of $Y$. For this, we split the series again, using the first $70 \%$ (training data) for calibrating the model and reserved the remaining 30\% (test data). Given an observed index values and the fitted copula model, we generated samples for $Y$ following the process described above and computed an estimate of the expected streamflow value by averaging them out. We compared the estimated expected values of streamflow with the observed values in both datasets (training and test) by computing Pearson and Spearman correlation between them.

On a second approach, instead of computing the expected value and using it as a forecast as we previously explained, we estimated quantiles of the conditional distribution and used them as boundaries of confidence intervals for streamflow and predictors for extreme seasonal events. Given an observation of the index, we estimated quantiles $5^{\text {th }}$ and $95^{\text {th }}$ of the streamflow given the index observation by sampling 1000 values of $Y$ and computing the corresponding quantiles of the sample. For this second approach we always fitted our model to the whole dataset. We are aware that by fitting the whole data set, we are only estimating training error, which may not fully agree with forecast error. However, as we count with less than 170 data points, and the aim of the second approach is measuring a 5\% frequency event, splitting into training and test sets would leave us with very few positive events to estimate the test error correctly. Anyways, we are moderately optimistic with respect to how much the results we present could change for data 
not previously observed. This optimism is based on the initial results we obtained about the quality of the copula fits in a test set, which is always inferior but still reasonable.

Using the quantile estimations, we first computed the number of times an observed value of $Y$ lies outside the confidence interval formed by the estimated $5^{\text {th }}$ and $95^{\text {th }}$ quantiles. We expect this value to be around $10 \%$ of the total samples. Second, we kept the $95^{\text {th }}$ quantile only and used it as a way of predicting evacuations. For this purpose, we built a binary variable indicating evacuation, using river heights data [meters] for the period December-1974 to November-2016 in the Túnel Subfluvial station (Paraná River). We also obtained this data from the SRH. We computed the following variable: for each season of the period, we checked if the evacuation level stipulated by Prefectura Naval Argentina, ${ }^{2}$ which is set at 5 meters for the Túnel Subfluvial station, was exceeded at least once. In this case, we tagged the season as evacuation; if not, we kept is as non-evacuation. In this way, we turned height data into a binary vector with trimester period resolution, assigning a 0 to the periods tagged as non-evacuations and a one to the periods tagged as evacuation.

For the evaluation of the performance of the estimated $95^{\text {th }}$ quantile as a predictor of evacuations we built the Receiver Operating Characteristic (ROC) curve (Robin et al., 2011) using the expected $95^{\text {th }}$ percentile as the explanatory variable and the evacuation variable as the binary response. This curve measures the sensitivity versus the specificity of a binary classification model for different cut points in the explanatory variable. Each point in the ROC curve represents the sensitivity and one minus the specificity we obtain if we put a threshold on the explanatory variable, and predict a one in the response variable whenever the value is above the threshold and zero if not. Sensitivity and specificity are terms that were first introduced by

\footnotetext{
${ }^{2}$ https://contenidosweb.prefecturanaval.gob.ar/alturas/mapa.php
} 
Jacob Yerushalmy (1947). The first one (sensitivity) corresponds to the capability to correctly predict a positive case and is defined as the ratio between the number of times the model correctly predicted the evacuation and the number of times evacuation actually occurred. The second one (specificity) is related to the ability to measure the proportion of negatives cases that are correctly identified as such and is defined as the ratio between the number of times the model correctly predicted that there will be no evacuation and the number of times that evacuation did not occur. The ROC curve uses one minus specificity (also called false positive rate), which is the proportion between the number of times the model wrongly predicted an evacuation and the number of times there was no evacuation.

Furthermore, a derived metric for evaluation of the performance of the prediction is the area under the ROC curve, presenting values between zero and one, the further from 0.5 this value is, the better the performance of the predictor.

Finally, we picked two values of the expected $95^{\text {th }}$ quantile of discharge that we would use as thresholds to predict an evacuation alarm, i.e. each time the expected $95^{\text {th }}$ quantile is above the threshold we predict there will be an evacuation. We used the values of specificity, sensitivity and third metric called precision to pick those optimal thresholds. The precision of a prediction is the ratio between the number of times the model correctly predicted an evacuation and the number of times the evacuation was predicted, which means it is a metric conditioned in the forecast (when model forecasted the evacuation).

The first value was picked as the one that optimizes a metric called F-score. The F-score is a useful metric to evaluate the performance of the model, that takes into consideration precision and sensitivity. It is computed as the harmonic mean between both quantities. The second value was picked visually from the ROC curve. We observed that in our case the 
maximum value of the F-score corresponds to a threshold where the ROC curve presents a noticeable change in slope, meaning that sensitivity and one minus specificity start to change at a different rate. Inspecting the curves, we also noticed that there is another threshold where they present a similar change in slope. We also picked that value, which is usually a more conservative option, meaning that using it will yield a higher amount of events predicted as evacuation, thus triggering more alarms with a higher proportion of false positives but covering more cases when an evacuation actually happens.

Finally, for both thresholds we computed contingency tables and performed a chi-squared test to test the null hypothesis of independence between predicted and observed evacuation with $95 \%$ of confidence.

\section{Results}

Exploring the discharge-climatic index relation

Based on the Augmented Dickey-Fuller and Phillips-Perron test, we rejected the nonstationary null hypothesis with a p-value below 0.05 for all the series in consideration. This is an essential assumption for most of the methods used in this work. We studied the relation between the variable pairs Túnel Subfluvial-NIÑO 3.4 and Paso de los Libres-NIÑO 3.4 using first the cross-correlation function, which we present in Figure 3. For the first pair is easy to see that the maximum correlation between lagged series was obtained for a lag of one and two seasons, while for the second pair it was obtained for a lag of one season.

The presence of significant waves in the paired time series was analyzed using the cross and coherence wavelet methodology. This joint study of seasonal discharges and NIÑO 3.4 
showed significant waves in different periods with some phase shift between the variables. Figure 4 shows the relation between Túnel Subfluvial and NIÑO 3.4 using the wavelet coherence methodology. A significant period can be observed from the beginning of the recorded period until the 1980s with seasonal periods between $8 \Delta t$ ( 8 seasons -2 years) and $16 \Delta t$ ( 4 years). Given the inclination phase (black arrows in the plot), we determined that, on average, the phase shift was nearly $2 \Delta t$.

Moreover, significant waves were observed in both seasonal time series after the end of the twentieth century, with wavelengths of 4 to 8 seasons, and 8 to 16 seasons, and around $16 \Delta t$. In these three examples, the average phase shift is $2 \Delta t$. We already analyzed this relation in $100-$ year periods for both measurement stations in Meis and Llano (2019), where a relationship between the climatic index and its dominance regarding streamflow was observed. For the Paso de los Libres and NIÑO 3.4 pairs, we observed the same phase shift (Figure not shown).

Based on these findings, we established a $2 \Delta t$ phase shift (with $\Delta t$ equal to 1 season) between the seasonal discharge variable and the seasonal climatic index. In the rest of this work, whenever we considered pairs of index-streamflow series, the climatic index series was always shifted $2 \Delta t$ in time to make significant waves of both series match temporally. Additionally, the Spearman coefficient was estimated considering the phase shift and in both pair of time series, finding a coefficient around 0.30 (p-value equal to 0.00010) for Túnel Subfluvial-NIÑO 3.4 and 0.20 (p-value equal to 0.017) for Paso de los Libres- NIÑO 3.4. We represent these relations in a dispersion plot for Túnel Subfluvial-NIÑO 3.4 (Figure 5). A positive relation between both variables can be noticed, meaning that when the index values are higher, the discharge values are also higher. This result matches the above-mentioned results for the relation between ENSO and streamflow in LPB stations. 


\section{A model of the streamflow-climatic index relation}

The first step of the copula method for fitting the joint distribution of each pair of series was estimating the marginal distributions. As described in the methodology section, we

considered different classical distribution functions (Normal, Lognormal, Gamma, Gumbel, Weibull) for each gauging station, and we estimated each parameter distribution using the maximum likelihood method. Additionally, we performed the corresponding goodness of fit tests. The fitted distributions and parameters can be found in Table II, III. We also plotted the theoretical distribution quantiles against the empirical quantiles' distribution, a procedure known as Q-Q plot (Figure 6), with a 5\% significance (Fox and Weisberg, 2019). Also, a histogram with the observed data and the proposed theoretical density function is shown. In both figures it can be verified that the fit is coherent.

In Table II, it can be observed that the Lognormal distribution and the Gumbel distribution can fit the measured data for seasonal discharges in the Túnel Subfluvial station. We noticed that the variable has a right tail asymmetry, and both analytical functions can fit that behavior. However, we picked Gumbel as a marginal distribution as it is a better fit according to the AIC criterion. We also see difference in favor of the Gumbel distribution fit in the Q-Q plot (Figure 6).

Regarding the Paso de los Libres station, the Weibull and Gumbel theoretical distributions can fit the seasonal streamflow data with a 5\% significance, but according to the AIC criterion, the Gumbel function should be employed (Table III); this is shown in Figure 7, which plots the theoretical Gumbel fit with the observed data. 
As expected, the Normal distribution has the best fit for the seasonal NIÑO 3.4 data with $5 \%$ of significance. Figure 8 shows how the theoretical model - the Normal distributionrepresents the observed data, although specific extreme values can be seen that slightly differ from a Normal distribution. The fit that we show here for seasonal NIÑO 3.4 is based on the same analysis period as for Túnel Subfluvial.

Using the theoretical marginal distributions with the better fit, we selected the copula function that better describes the bivariate relation between each data pair.

As described in the methodology section, we selected the best copula function among several families, using the algorithm proposed by Schepsmeier et al., 2018 (which considers more than thirty families of copulas), and according to the AIC criterion, the Joe copula (Eq. 5) was most suitable for both data pairs (NIÑO 3.4 - Túnel Subfluvial and NIÑO 3.4 - Paso de los Libres). It is worth to notice that we were interested in studying the joint probability of extreme events in greater depth, particularly events where both streamflow and climatic indices were above the 95th percentile, but not all copula families can accurately model extreme values. The copula we chose (Joe) is adequate to determine upper tail dependence (Van-Nam et al., 2013).

$$
\mathrm{C}_{\theta}(\mathrm{u}, \mathrm{v})=1-\left[(1-\mathrm{u})^{\theta}+(1-\mathrm{v})^{\theta}-(1-\mathrm{u})^{\theta}(1-\mathrm{v})^{\theta}\right]^{1 / \theta} \quad \text { with } \theta \geq 1
$$

With $u, v$ the uniform variables, and $\theta$ the estimated parameter. The upper tail dependence coefficient for this copula is $2-2^{\frac{1}{\theta}}$. While for the lower tail is 0 .

Table IV shows the parameter $\theta$ for each fit and the goodness of fit results for the copula functions. It contains p-values for the Cramer-Von Mises, and Kolmogorov-Smirnov tests obtained through Bootstrap resampling. In both cases, and according to the p-values $(0.21$ and 0.39), the null hypothesis is not rejected, and the Joe copula family with $95 \%$ of confidence fits 
the pair NIÑO 3.4 - Túnel Subfluvial. We used an analogous procedure for the pair NIÑO 3.4 Paso de los Libres, with similar results.

\section{Model validation}

We calibrated the copula to the training data that were selected randomly, which turned out to be of Joe's family again. We ran goodness-of-fit tests for the obtained model both in training and test data. In all cases, the null hypothesis of our tests is not rejected, indicating that the proposed model fitted both series. The p-values obtained were 0.19 and 0.38 for the CVM test, and 0.20 and 0.44 for the KS test (training and test sets respectively).

Also, we repeated the procedure by splitting the series temporally. Again, we obtained a Joe family copula in the training series, and the null hypothesis of the goodness of fit tests was not rejected in any case, yielding p-values 0.19 and 0.37 for the CVM test and 0.25 and 0.36 for the KS test (training and test respectively). Note that this second approach provided out-ofperiod validation for the model.

We replicated the above procedure for Paso de los Libres station. In this case, the validation of the model could only be done when the data was split randomly. This could be related to a lesser signal of ENSO in the Uruguay basin than the Parana basin, combined with not sufficient amount of data. In the case of temporal splitting, the proposed algorithm could not find a suitable copula function that fitted the training set.

Forecasting from the joint distribution 
While we fitted a bivariate distribution to our pairs of series, we always considered seasonal discharge to be the response variable and index values to be the explanatory one. Therefore, it made sense to use the model as a tool for forecasting in the following way: once we observed an index value, we conditioned the joint distribution to that value and used the obtained streamflow distribution to predict quantities of interest. Observe that as the index series has a phase shift of $2 \Delta t$ (half a year), we were forecasting within that time horizon.

To validate these predictions for Túnel Subfluvial discharge, we split the series again, using the first $70 \%$ (training data) for calibrating the model. We generated predicted streamflow values, following the above procedure, and computing the conditional expectation for the whole series and compared with the observed values in both datasets (training and test). In both cases, we computed the correlation between observed and forecasted values. The results showed that the Pearson and Spearman correlation between observed and predicted streamflow values were 0.54 and 0.32 respectively (p-values equal to $3.789 \mathrm{e}-10$ and 0.00050 ) for the training series, and 0.52 and 0.37 (p-value equal to 0.00024 and 0.011 ) for the test series. We exhibit scatter plots for observed and predicted values in Figure 9 (a- train, b- test and c- whole dataset). Furthermore, we performed the same correlation analysis for data points corresponding to values of NIÑO 3.4 above and under its median separately. Results showed a healthy relationship for the positive phase of the index and almost null for the negative phase. Finally, we repeated the same procedure using random train/test splits (instead of using the initial $70 \%$ of the series as training set and reserving the final $30 \%$ as test set) and obtained Pearson and Spearman correlations of 0.51 and 0.27 (respectively) on the train set, and 0.49 and 0.21 on the test set, with p-values equal to $8.202 \mathrm{e}-09$ and 0.0045 and 0.00033 and 0.02 , respectively. 
We explored a second approach for forecasting, which is more focused on the prediction of extreme events of streamflow. We followed the same idea as above: once we observed an index value, we could use the model to estimate a conditional distribution for the corresponding streamflow data point. In this case, instead of computing the expected value and using it as a forecast, the idea was estimating quantiles of the conditional distribution and using them as boundaries of confidence intervals for streamflow. For example, we would expect that streamflow does not surpass the 95\%-quantile of the conditional distribution with $95 \%$ of confidence.

In this case, as we explained in the methodology section, we fitted the model to the whole series, thus we only report one value for each metric and not two (training and test). Following the same procedure as in the previous case, we generated samples for the conditional distribution for each observation of the index. We estimated $5 \%$ and $95 \%$ quantiles of the conditional distribution from these samples, generating confidence intervals of Figure 10 for the Túnel Subfluvial series. We ended up with the top and bottom series for streamflow, inferred from the index series. The theoretical result that should hold is that for any time point, the streamflow should be under the top series value with $95 \%$ confidence and over the bottom series value with 95\% confidence too. To assess the accuracy of the calibration of these series we computed, for each value from $5 \%$ to $95 \%$ in steps of $5 \%$, what was the proportion of streamflow observations that lied below the estimated quantile. Results can be seen in Figure 11 for Túnel Subfluvial, together with the expected theoretical proportion.

Forecasting analysis was not performed for Paso de los Libres-NIÑO 3.4, mainly because we found that model validation does not hold temporally for that series. This indicates that although the model could be calibrated to the whole dataset and this calibration was validated 
with random splits, we do not have enough data to carry out-of-period validation, and therefore it might not be wise to generate forecasts for this series.

\section{Evaluation of the 95th quantile as an evacuation measure of early evacuation}

We added a second use to the previously computed quantiles. We proposed to evaluate and quantify a possible system of evacuation alert using the expected $95^{\text {th }}$ percentile series for the distribution for Túnel Subfluvial discharge conditional to the previously observed NIÑO 3.4 index.

As described in the methodology section, a ROC curve was built (Figure 12) between the binary variable that discriminates when the height of the river in Túnel Subfluvial station was

over 5 meters at least once in the trimester (response variable), and the conditional $95^{\text {th }}$ percentile discharge estimated given the NIÑO 3.4 index (explanatory variable). We computed the area under the curve, which is a metric about the predictive power of the explanatory variable, and obtained a value of 0.83 , which is indicative of a strong relation.

From this ROC curve, we picked two thresholds on the expected $95^{\text {th }}$ percentile that can be used for predicting an evacuation. For each of those values, we obtained a new binary variable of predicted evacuation, which is equal to one when the expected $95^{\text {th }}$ percentile is higher than the threshold and zero otherwise, obtaining a total amount of 166 vectors.

The first of the thresholds was selected as the one that maximizes F-score. We used the library Performance Estimation library for R (Torgo, 2016) to compute F-scores for different thresholds and obtained a maximum of 0.6 at the threshold $23147.76\left[\mathrm{~m}^{3} / \mathrm{s}\right]$. We show the location of this value in the ROC curve In Figure 13, it can be appreciated that at that point, there is a change in the slope of the curve. For this threshold value, the corresponding contingency 
table, Table V, was obtained. Taking into account Table V, a chi-squared test was done to evaluate the association between the variables with a $95 \%$ of confidence, since the p-value obtained was 0.0004998 the null hypothesis was rejected, concluding that there is enough evidence to indicate an association between the variables.

The second threshold was selected in a visual manner, looking for a second change in the slope of the ROC curve. This threshold has an associated value equal to $20708.24\left[\mathrm{~m}^{3} / \mathrm{s}\right]$. Moreover, in Figure 14 we show the ROC curve, with vertical and horizontal lines associated with 1-specitificty and sensitivity values, respectively, for that fixed threshold. This second threshold is a more conservative alert system, meaning that more alerts are emitted, improving the sensitivity (near 90\%) at the cost of generating a much higher quantity of false positives (near to $45 \%$ ). From this new threshold the contingency table was computed, Table VI. Besides, we considered the chi-squared test to evaluate the association among the variables with $95 \%$ confidence, obtained a p-value equal to $2.188 \mathrm{e}-07$, enough to infer an association between the variables.

In summary, two thresholds were proposed as alert systems from a possible evacuation. In this way, not only we studied the general relation between the expected discharge variable and the alert system for evacuation but also the performance of these alert systems was assessed.

\section{Comparison between the theoretical model and the observed data}

We performed a simulation using the copula model to observe and compare the theoretical function with the measured data. The results that are shown are for the Túnel Subfluvial and NIÑO 3.4 pairs (Figure 15). Again, it is possible to observe a positive relationship between each variable in the theoretical behavior (black dots) as well as in the real data (red 
dots). This relation follows from the close positive correlation between NIÑO 3.4 and precipitation in the LPB region, as reported in the bibliography. Additionally, it is essential to mention that the data distribution for extreme values shows adequate theoretical modeling in the upper tail. For Paso de los Libres (Figure not shown), we also obtained an adequate simulation for the observed data. In this sense, the modeling was satisfactory for the two study cases.

\section{Probability estimates for extreme events}

In order to determine the probability of joint occurrence in the class of situations that are of interest in this article, we estimated the cumulative probability for the bivariate relation. This analysis is helpful in estimating the probability of extreme discharge events (in this article, those above the 95th percentile) and relate them to climatic phenomena. In this sense, given that we are studying a bivariate relation, it is also necessary to fix a climatic index threshold. Due to the occurrence of particularly extreme events in seasonal streamflow and taking into account the phase shift of 2 seasons from the climatic index, we observed that the seasonal indices values from NIÑO 3.4 associated with those events were above the 95 th percentile. Figure 16 shows the bivariate probability for Túnel Subfluvial and NIÑO 3.4. The red lines highlight the quadrant that is associated with extreme events, fixed by the 95th-percentile thresholds for both variables. According to this theoretical model, the joint probability for extreme events was $2.2 \%$. The

relation between Paso de los Libres and NIÑO 3.4 showed similar results, and for that reason, the figure is not shown.

Bivariate return periods in extreme events 
A useful metric that can be estimated from the joint distribution of the pair of series is the return period (Salvadori and De Michele, 2004). In this sense, the distribution data for Túnel Subfluvial-NIÑO 3.4 (black dots), and the return period isolines which were obtained with the probability function we have adopted (Figure 17). If we analyze extreme events of seasonal streamflow (above the 95th percentile, red line) associated with NIÑO 3.4 values higher than the 95th percentile (1.54), we observe a return period once around 15 years according to empirical data, and 11.5 years according to simulated data. The events that are above those thresholds are autumn/winter 83, winter 92, and autumn 98 for seasonal streamflow, as well as summer 98 and summer 16. Also, it is interesting to point out that the return period of each variable for a 95th percentile would have been five years. In this way, if both variables were independent, the result would have been considerably larger, achieving a 100-return period for the previous joint threshold. In other words, the last result reveals a strong dependence between both variables.

Moreover, our analysis shows that extreme events for both series seem to be strongly correlated, so it is essential and necessary to model the index-streamflow relation. Additionally, it should be noticed that although there were certain events whose values were above the 95th percentile $\left(21916.61\left[\mathrm{~m}^{3} / \mathrm{s}\right]\right)$, the index value was below that percentile; yet these events count as El Niño events (summer 83, autumn 95). Indeed, events in the upper right tail belong to the warm ENSO phase, not to normal streamflow conditions (they are substantially above the mean). Finally, in Figure 17, it is possible to observe the most extreme seasonal event, winter 83 . The combination of extreme seasonal discharge and extreme seasonal positive ENSO 3.4 index for this event has a close to 200 -year return period. Such a return period is not surprising as this ENSO event is considered exceptional (Camilloni and Barros, 2000). 
Regarding the relation between Paso de los Libres and NIÑO 3.4 (Figure 18), we observed extreme events with streamflow values above the 95th percentile and above the 95th percentile in the seasonal climatic index (1.39). By computing the fitted return period, we observe that events of this magnitude occur, on average, every 14.5 years. Among the observations, we have five such events in the study period (autumn/winter 83, winter 92 , summer/autumn 98). Moreover, there were events above the 95th percentile for streamflow $\left(10050.38\left[\mathrm{~m}^{3} / \mathrm{s}\right]\right)$, but with climatic index values below that percentile (spring 82, 97, and 2002). Additionally, winter 1984 was close to the 95th percentile threshold for seasonal streamflow. This was an isolated event, as it is not associated with a warm ENSO phase. The existing bibliography mentions the substantial floods that occurred in the LPB region for that season (Righi and Souza Robaina, 2010), where the authors emphasize that precipitation showed extreme values, possibly due to other physical causes.

Both analyses show not only the 95th-percentile thresholds but the 90th-percentile thresholds, both for the seasonal streamflow and the seasonal climatic index (Figures 17 and 18). In the Túnel Subfluvial-NIÑO 3.4 analysis the return period for this type of event was around five years, while in Paso de los Libres, the period was slightly lower.

\section{Conclusion}

Our analysis proposed a method for estimating the joint probability density function of the combined phase shift for climatic index and seasonal discharge. The main aim was to provide a useful tool for anticipating extreme events in a runoff, as we are studying the interaction of the observed index with the streamflow occurring two seasons later. Estimating the joint distribution 
of a pair of response/explanatory variables can be useful in many aspects. In this work, we derived metrics that are particularly useful for quantifying some known relationships as well as proposed some simple ideas for forecasting. However, the picture of possible applications far exceeds what is presented here, as the joint distribution of a pair of variables contains all the available probabilistic information in them. For example, the information about the joint distribution can surely be used as an input for more complex models.

In our case, this tool enabled us to quantify probabilities (and their associated return periods) for certain joint extreme events which already occurred in recent years. A metric like this one can be useful for monitoring the occurrence of extreme events in the streamflow variable and in the climatic index which were related to extreme ENSO events (Takahashi and Dewitte, 2016). Moreover, we provided two possible approaches for seasonal discharge forecasting. The first one, which follows the line of Khendun et al. (2014), is about computing the expected value of discharge given the observed index value and using it as a forecast. The second one is about computing confidence intervals for streamflow, given climatic index values. In the first case, we find that there is a signal in the prediction by computing a significant correlation between observed and predicted values. In the second case, the forecasted quantiles are especially useful as they provide a simple way of obtaining a value that the streamflow will not surpass with an absolute confidence. The $95 \%$ quantile of the conditional distribution seems to be a reasonable metric to monitor, as it is tight enough to be meaningful (not raising the alarm on every period) but at the same time be fulfilled with reasonable confidence.

Additionally, our model was validated by different approaches showing that it could be considered for monitoring the relationship between streamflow ENSO and the gauging stations from the LPB. We validated our model temporally for Túnel Subfluvial, given us the certainty 
that both the metrics we monitored and the forecasts we produced should be meaningful moving forward in the future. Moreover, we also checked the consistency of the thresholds we computed for streamflow values.

The performance of the model considered for Túnel Subfluvial station was evaluated by different metrics. We computed the area under the ROC curve built using a dichotomic variable obtained from discharge height as objective variable and the $95^{\text {th }}$ percentile expected discharge as predictor. Using the information provided by this curve, we explored the possibility of using $95^{\text {th }}$ percentile expected discharge to build a binary variable that anticipates evacuations. We set two different thresholds on this variable and examined the quality of the prediction obtained if we anticipate an evacuation each time the $95^{\text {th }}$ percentile expected discharge is above those thresholds. For both cases, we computed contingency tables and carried out a chi-square test where we rejected the null hypothesis of lack of association between predicted and actual evacuations with $95 \%$ confidence. We also computed sensitivity and specificity in all the cases.

In general, our work provides an approach for more deeply studying the relation between climatic indices and discharge in a way that is not currently found in the literature that has been written about these two variables in the region. Moreover, we propose a simple yet new way of employing the results obtained with this methodology in the case of meteorological variables.

To conclude, it is worth mentioning that our procedure shows that given a certain threshold for the climatic index, it is possible to quantify the probability of extreme discharge events with a confident anticipation. In this sense, we were able to provide a simple and validated climatic probabilistic way of monitoring the occurrence of extreme events in two rivers of great socio-economic importance in the southern region of the LPB from a well-studied variable. In this sense, in the Túnel Subfluvial case, the methodology foresees the occurrence of 
events higher than the $95^{\text {th }}$ percentile on both variables once every 11.5 years, indicating that we expect roughly half of the extreme streamflow events to correspond to extreme index events. Early identification of these types of events might help to mitigate their negative impact.

\section{Acknowledgment}

We thank anonymous referees for their valuable comments and critical reading of the article. This research was supported by CONICET under Grant 11220130100806, 20020170100330BA from the Universidad de Buenos Aires and PICT-201-0377 from ANPYCT, Argentina.

\section{References}

AghaKouchak, A., Bárdossy, A., Habib, E., 2010. Conditional simulation of remotely sensed rainfall data using a non-Gaussian v-transformed copula. Advances in Water Resources. Vol. 33(6). 624-634.

AghaKouchak, A., Cheng, Ll, Mazdiyasni, O., Farahmand, A., 2014. Global warming and changes in risk of concurrent climate extremes: Insights from the 2014 California drought. Geophys. Res. Lett. Vol. 41. 8847-8852.

Antico, A., Torres, M.E., Diaz, H.F., 2015. Contributions of different time scales to extreme Paraná floods. Climate Dynamics. Vol. 46. 3785 - 3792. 
Berri, G., Ghietto, M., García, NO., 2002. The Influence of ENSO in the Flows of the Upper Paraná River of South America over the Past 100 Years. American Meteorological Society. Vol. 3. $57-65$

Camilloni, I., and Barros, V.R., 2003. Extreme discharge events in the Paraná River and their climate forcing. Journal of Hydrology. Vol. 278, 94-106.

Camilloni, I. A., and Barros, V. R., 2000: The Paraná river response to El Niño 1982-83 and 1997-98 events. J. Hydrometeorology, 1, 412-430.

Cavalcanti, I.F.A., Carril, A.F., Penalba, O.C., Grimm, A.M., Menéndez, C.G., Sanchez, E., Cherchi, A., Sorensson, A., Robledo, F., Rivera, J., Pántano, V., Bettolli, L.M., Zaninelli, P., Zamboni I., Tedeschi, R.G., Dominguez, M., Ruscica, R., Flach, R., 2015. Precipitation extremes over La Plata Basin - Review and new results from observations and climate simulations. Journal of Hydrology. Vol. 523. 211-230.

Cong, R.G, Brandy, M., 2012. The Interdependence between Rainfall and Temperature: Copula Analyses. The Scientific World Journal. Vol. 2012. 1-11.

Wei Fang, W., Huang, S., Huang, G., Huang, Q., Wang, H., Wang, L., Zhang, Y., Li, P., Ma, L., 2018. Copulas-based risk analysis for inter-seasonal combinations of wet and dry conditions under a changing climate. International Journal of Climatology, DOI: 10.1002/joc.5929.

Fox, J. and Weisberg, S., 2019. An R Companion to Applied Regression, Third Edition, Sage.

Fuller, W. A., 1996. Introduction to Statistical Time Series, second ed., New York: John Wiley and Sons. 
Ganguli, P., Reddy, M J., 2013. Analysis of ENSO-based climate variability in modulating drought risks over western Rajasthan in India. Journal of Earth System Science. Vol. 122. Issue 1. 253-269.

García, NO., Vargas, WM., 1998. The temporal climatic variability in the "Rio de la Plata" basin displayed by the rivers discharges. Climatic Change. Vol. 38, 359-379.

Grinsted, A., Moore, J. and Jevrejeva, S., 2004. Application of the cross wavelet transform and wavelet coherence to geophysical time series. Nonlinear Processes in Geophysics. Vol. 11, 561566.

Khendun, C.P, Mishra, A.K, Singh, V.P, Giardino, J.R., 2014. A copula-based precipitation forecasting model: Investigating the interdecadal modulation of ENSO's impacts on monthly precipitation. Water Resources Research, Vol. 50, 580-600.

Kiem, A., Franks, S., Kuczera, G., 2003. Multi-decadal variability of flood risk. Geophysical Research Letters, Vol. 30, no. 2, 1035.

Hofert, M., Kojadinovic, I., Maechler, M., Yan, J., 2017. Copula. cran.r-project.

Maraun, D. and Kurths, J., 2004. Cross wavelet analysis: significance testing and pitfalls. Nonlinear Processes in Geophysics. Vol.11, 505-514.

Meis, M., Llano, M.P., 2019. Hydrostatistical study of the Paraná and Uruguay Rivers. International Journal of River Basin Management. Vol. 17. 1-12.

Phillips, P.C.B, Perron, P., 1988. Testing for a Unit Root in Time Series Regression, Biometrika, 75, 335-346 
Popescu, I., Brandimarte, L., Peviani, M., 2014. Effects of climate change over energy production in La Plata Basin. International Journal of River Basin Management. Vol. 12. 1-9

Re, M., Barros, V. R., 2009. Extreme Rainfalls in SE South America, Climatic Change 96:1-2, $119-136$.

Righi, E., de Souza Robaina, L.E., 2010. Enchentes do rio Uruguai no rio Grande Do Sul entre 1980 e 2005: uma análise geográfica. Sociedade \& Natureza. Vol. 22. 35-54

Robin, X., Turck, N., Hainard, A., 2011. pROC: an open-source package for R and S+ to analyze and compare ROC curves. BMC Bioinformatics. Vol. 12, 77

Salvadori, G., De Michele, C., 2004. Frequency analysis via copulas: Theoretical aspects and applications to hydrological events. Water resources research. Vol. 40. 1-17

Schepsmeier, U., Stoeber, J. Brechmann, E.C., Graeler, B., Nagler, T., Erhardt, T., Almeida, C., Min, A., Czado, C., Hofmann, M., Killiches, M., Joe, H., Vatter, T., 2018. Statistical Inference of Vine Copulas. cran.r-project.

Siegel, S., 1985. Nonparametric statistical: for the behavioral sciences. 1st ed. Tokyo: McGrawHill Book Company

Sklar, A., 1959. Fonctions de répartition à n dimensions et leurs marges. Publ. Inst. Statist. Univ. Paris. 8: 229-231.

Takahashi, K., Dewitte, B., 2016. Strong and moderate nonlinear El Niño regimes. Clim. Dyn. Vol. 46. 1627-1645.

Torgo, L., 2016. An Infra-Structure for Performance Estimation of Predictive Models. cran.rproject. 
Torrence, C. and Compo, G., 1998. A Practical Guide to Wavelet Analysis. Bulletin of the American Meteorological Society. Vol.79, 61-78.

Van-Nam, H., Vladik, K., Songsak, S., Komsan, S., 2013. Uncertainty Analysis in Econometrics with Applications. Springer, Berlin.

Ward, P., Jongman, B., Kummu, M., Dettinger, M., Weiland, F., Winsemius, F., 2014. Strong influence of El Niño Southern Oscillation on flood risk around the world. PNAS. Vol. 111, no. $44,15659-15664$.

Yerushalmy, J., 1947. Statistical problems in assessing methods of medical diagnosis with special reference to x-ray techniques. Public Health Reports. Vol. 62 (2). 1432-39.

Zhang, L., Singh, V., 2012. Bivariate Rainfall and Runoff Analysis Using Entropy and Copula Theories Entropy.Vol.14. 1784-1812. 
Table I: Data from the reference gauging stations (Túnel Subfluvial and Paso de los Libres) provided by the Argentine Undersecretariat for Water Argentina, and NIÑO 3.4 index provided by NOAA ESRL Physical Sciences Division.

\begin{tabular}{|c|c|c|}
\hline Data & Period & Latitude / Longitude \\
\hline $\begin{array}{c}\text { Túnel Subfluvial (Paraná } \\
\text { River) }\end{array}$ & $12 / 1974-11 / 2016$ & $31^{\circ} 43^{\prime} 11^{\prime \prime}, 60^{\circ} 31^{\prime} 03^{\prime}$, \\
\hline $\begin{array}{c}\text { Paso de los Libres (Uruguay } \\
\text { River) }\end{array}$ & $12 / 1974-12 / 2015$ & $29^{\circ} 433^{\prime} 17^{\prime \prime} \quad 57^{\circ} 04^{\prime} 57^{\prime \prime}$ \\
\hline NIÑO 3.4 & $12 / 1974-12 / 2016$ & \\
\hline
\end{tabular}


Table II: Seasonal streamflow fit and goodness of fit for the Túnel Subfluvial gauging station, according to different theoretical distributions, with a 5\% significance level.

\begin{tabular}{|l|l|l|}
\hline Theoretical Distributions & Parameters & Bootstrap p-valor \\
\hline Normal & $\begin{array}{l}\mu=15855.82 \\
\sigma=3347.81\end{array}$ & 0.006 \\
\hline Lognormal & $\mu=9.65$ & 0.30 \\
& $\sigma=0.20$ & \\
\hline Weibull & $k=4.57$ & 0 \\
\hline Gamma & $\lambda=1.709532 \mathrm{e}+04$ & 0.18 \\
\hline Gumbel & $\alpha=2.431058 \mathrm{e}+01$ & 0.62 \\
\hline
\end{tabular}


Table III: Seasonal streamflow fit and goodness of fit for the Paso de los Libres gauging station according to different theoretical distributions, with a 5\% significance level.

\begin{tabular}{|l|l|l|}
\hline Theoretical distribution & Parameters & Bootstrap p-value \\
\hline Normal & $\begin{array}{l}\mu=4776.1143 \\
\sigma=2842.095\end{array}$ & 0.007 \\
\hline Lognormal & $\mu=8.28477217$ & 0.012 \\
\hline Weibull & $\sigma=0.64$ & 0.905 \\
\hline Gamma & $k=1.7795657$ & \\
\hline Gumbel & $\lambda=5388.56$ & 0 \\
\hline & $\alpha=1684.6814030$ & 0.52 \\
\hline
\end{tabular}


Table IV: Fit and goodness of fit for the seasonal NIÑO 3.4 index using Normal theoretical distribution with a 5\% significance level (Cramer-Von Mises (CVM) and Kolmogorov-Smirnov (KS) tests).

\begin{tabular}{|l|l|l|}
\hline Pair & Parameter & p-value (CVM/KS) \\
\hline NIÑO 3.4-Túnel Subfluvial & $\theta=1.55$ & $0.21 / 0.39$ \\
\hline NIÑO 3.4-Paso de los Libres & $\theta=1.34$ & $0.31 / 0.24$ \\
\hline
\end{tabular}

Table V: Contingency table between the response variable (binary river height) and the binary discharge from the threshold obtained from the ROC curve that maximize the F-score.

\begin{tabular}{|c|c|c|c|}
\hline & Response & 0 & 1 \\
\hline Explanatory & 0 & 125 & 10 \\
\hline & 1 & 13 & 17 \\
\hline
\end{tabular}

Table VI: Contingency table between the response variable (binary river height) and the binary discharge from the threshold obtained from the ROC curve where a change in the slope of the curve was seen.

\begin{tabular}{|c|c|c|c|}
\hline & Response & 0 & 1 \\
\hline Explanatory & 0 & 76 & 3 \\
\hline & 1 & 62 & 24 \\
\hline
\end{tabular}




\section{Figure Captions}

Figure 1 Túnel Subfluvial (Paraná River) and Paso de los Libres (Uruguay River) gauging stations located in the La Plata Basin between $27^{\circ}$ to $33^{\circ} \mathrm{S}$.

Figure 2: Seasonal streamflow time series $\left(\mathrm{m}^{3} / \mathrm{seg}\right)$ for Túnel Subfluvial (top panel), Paso de los Libres (mid panel) and NIÑO 3.4 seasonal index (bottom panel).

Figure 3: Cross correlation function between seasonal NIÑO 3.4 and Túnel Subfluvial discharge (left), and NIÑO 3.4 and Paso de los Libres discharge (right). Blue lines represent the confidence intervals.

Figure 4: Wavelet coherence and significant phase difference between the seasonal NIÑO 3.4 index and the Túnel Subfluvial seasonal streamflow, with a 5\% significance level.

Figure 5: Relation between seasonal streamflow time series for the Túnel Subfluvial gauging station $[\mathrm{m} 3 / \mathrm{s}]$ and the climatic seasonal index NIÑO 3.4 with a phase shift equal to two trimesters.

Figure 6: Seasonal streamflow Q-Q plot (5\% of significance) and Gumbel theoretical quantiles for the Túnel Subfluvial gauging station (left). Seasonal streamflow probabilistic histogram and Gumbel probability density distribution for the Túnel Subfluvial gauging station (right).

Figure 7: Seasonal streamflow Q-Q plot (5\% of significance) and Gumbel theoretical quantiles for the Paso de los Libres gauging station (left). Seasonal streamflow probabilistic histogram and the Gumbel probability density distribution for the Paso de los Libres gauging station (right).

Figure 8: Q-Q plot (5\% of significance) for the seasonal NIÑO 3.4 index and Normal theoretical quantiles (left). Probabilistic histogram for the seasonal NIÑO 3.4 index, and Normal probability density distribution (right).

Figure 9: Scatter plots for observed and predicted values a) for train, b) for test and c) for the whole dataset.

Figure 10: Series of 5\% and 95\% quantiles of the estimated conditional distribution obtained from the observed index value for Túnel Subfluvial.

Figure 11: Proportion of observations that lied below the estimated quantile. 
Figure 12: The ROC curve between the response binary variable river height for Túnel Subfluvial gauging station and the expected 95-percentile streamflow considering the NIÑO 3.4 index.

Figure 13: The ROC curve between the response binary variable river height for Túnel Subfluvial gauging station and the expected 95-percentile streamflow considering the NIÑO 3.4 index. The red line represents 1 -specificity value, and the blue line the sensitivity value for the threshold that maximizes the F-score.

Figure 14: The ROC curve between the response binary variable river height for Túnel Subfluvial gauging station and the expected 95-percentile streamflow considering the NIÑO 3.4 index. The red line represents 1-specificity value, and the blue line the sensitivity value for the threshold that presents a change in the curve ROC growth.

Figure 15: Scatter plot for the seasonal NIÑO 3.4 index and seasonal discharge at the Túnel Subfluvial gauging station. Theoretical simulation in black dots and observed data in red dots.

Figure 16: Theoretical cumulative bivariate probabilistic function for seasonal discharge at Túnel Subfluvial and the NIÑO 3.4 index, using copula methodology.

Figure 17: Bivariate return periods for seasonal streamflow at Túnel Subfluvial and the NIÑO 3.4 seasonal index (black lines), observed data in black circles, and observed data with values above the 95th percentile is shown with red circles. The 90th and 95th percentiles were added to the plot (blue dashed lines and red lines, respectively).

Figure 18: Bivariate return periods for seasonal streamflow at Paso de los Libres and the NIÑO 3.4 seasonal index (black lines), observed data shown with black circles, and observed data with values above the 95th percentile are shown with red circles. The 90th and 95th percentiles were added to the plot (blue dashed lines and red lines, respectively). 


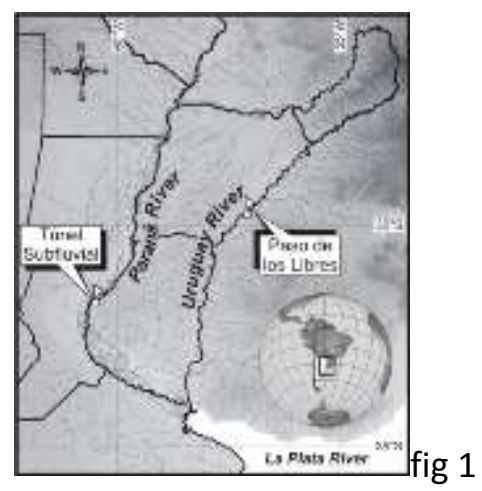



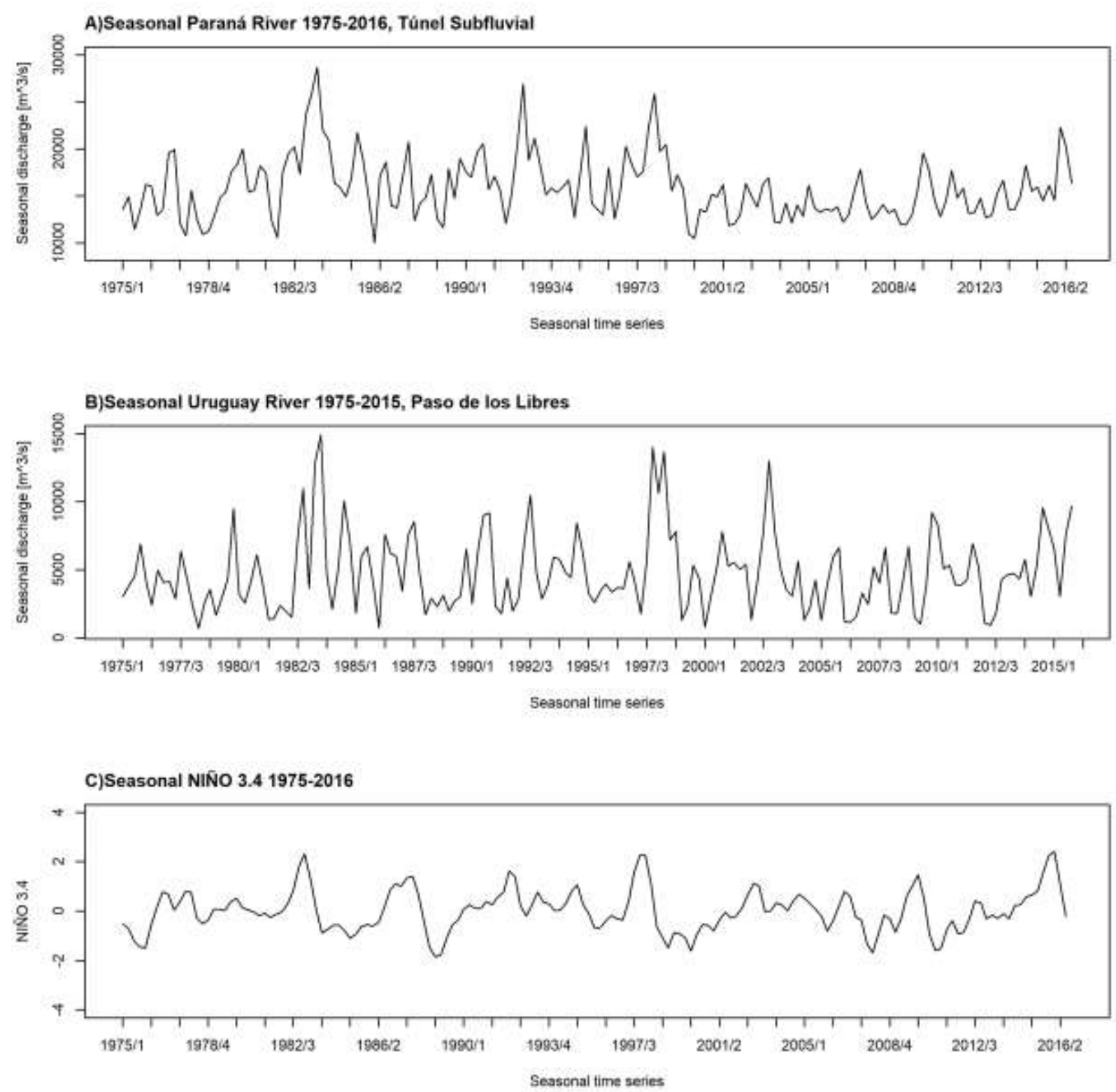

fig 2 
Fig 3

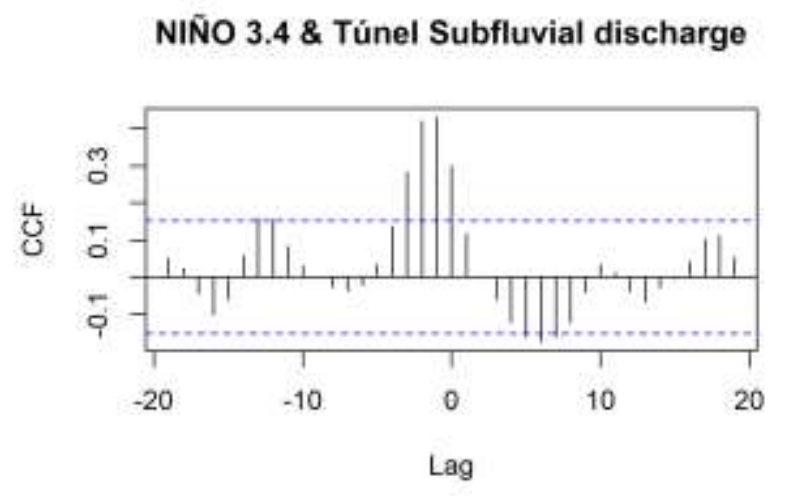

NIÑO 3.4 \& Paso de los Libres discharge
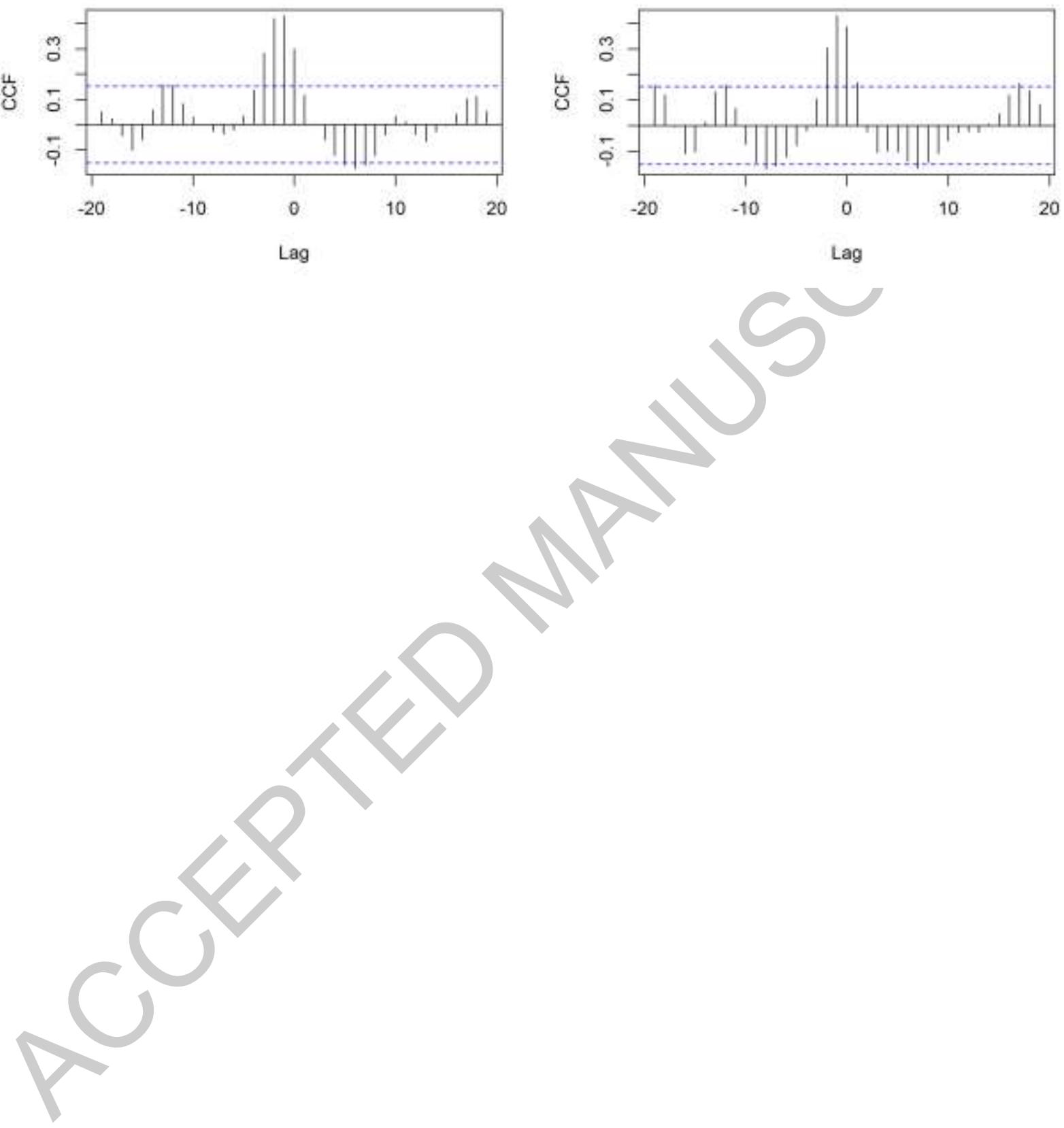
Fig 4

NIÑO 3.4-Túnel Subfluvial 1975-2016

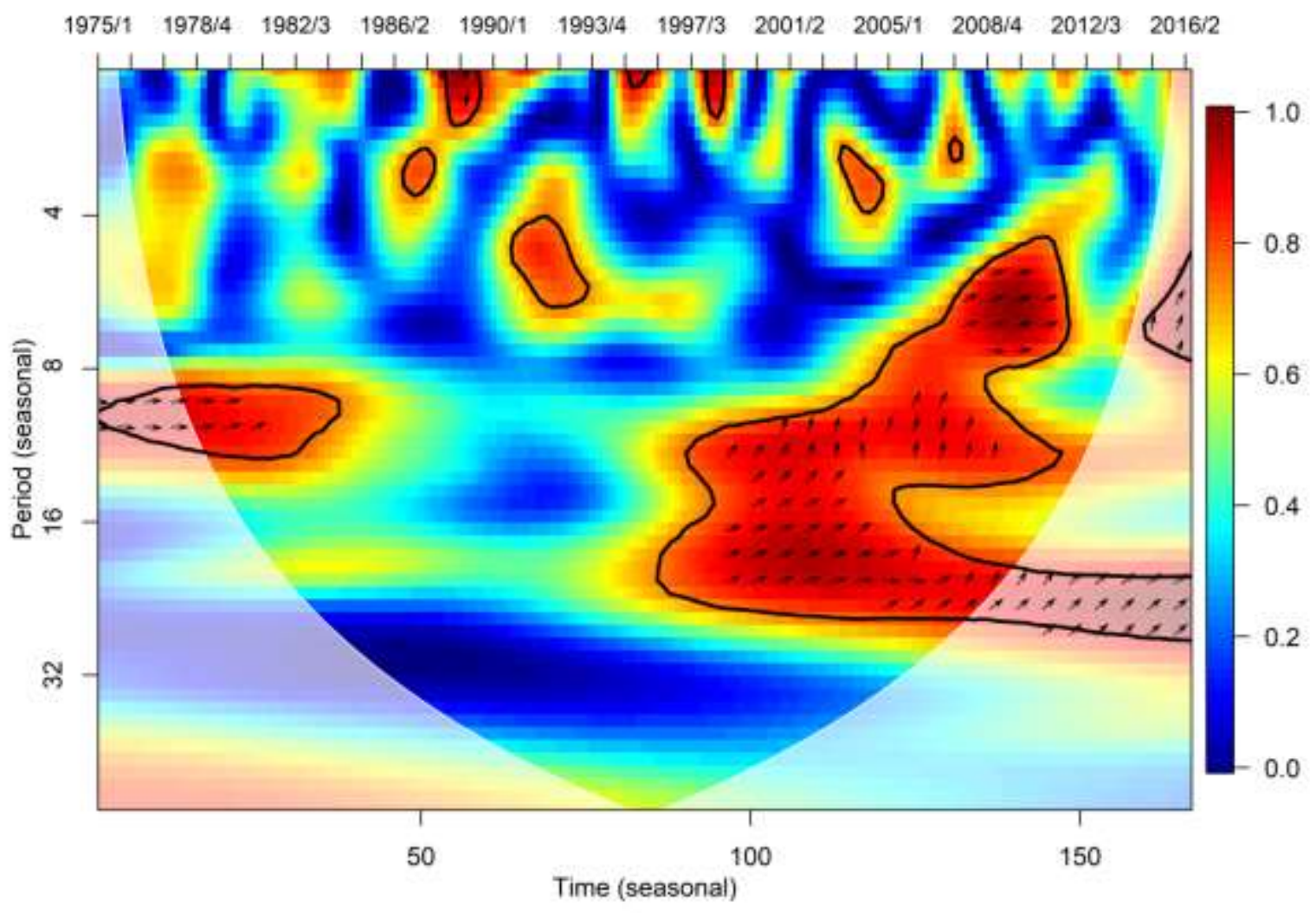


Fig 5

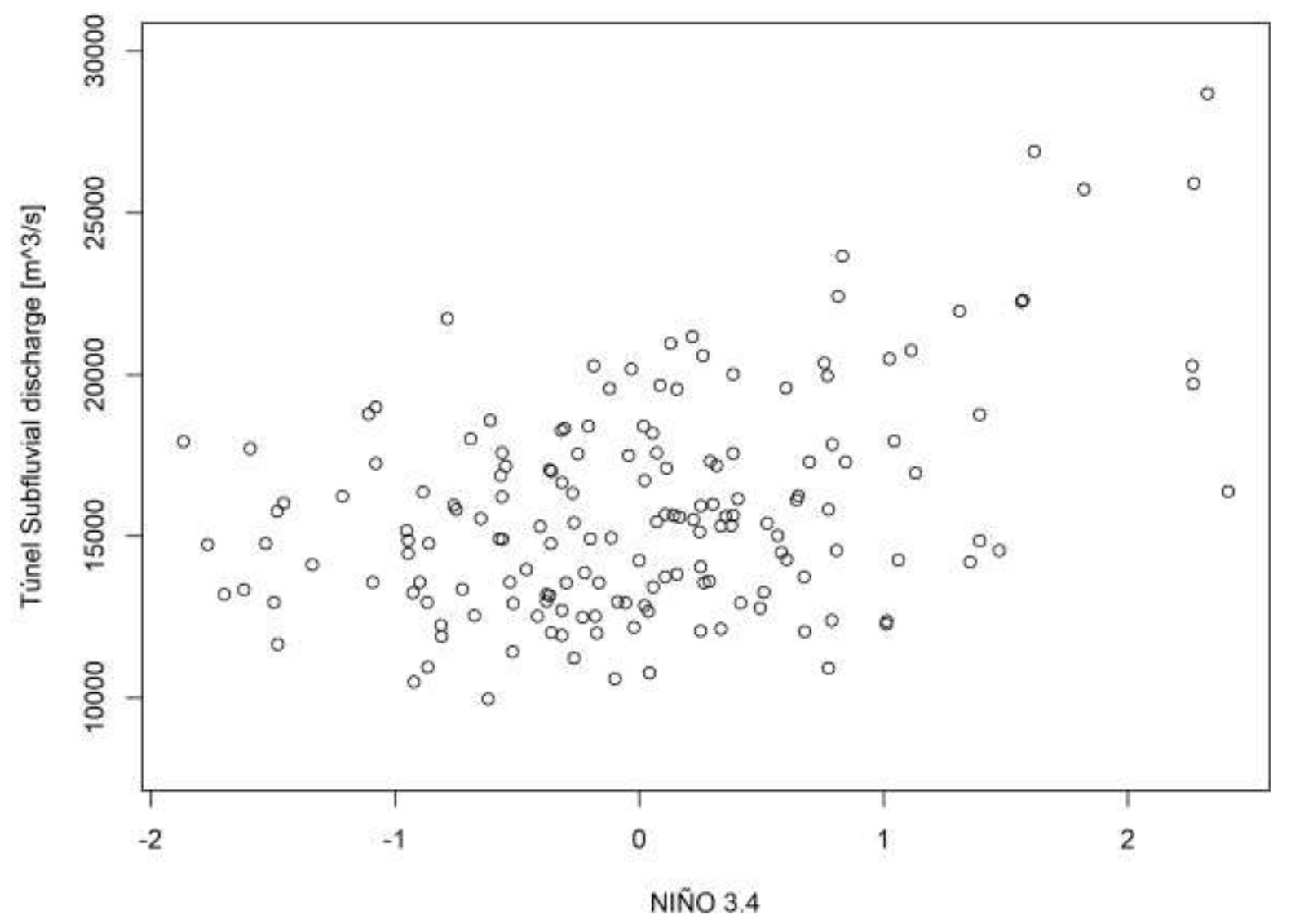


Fig 6

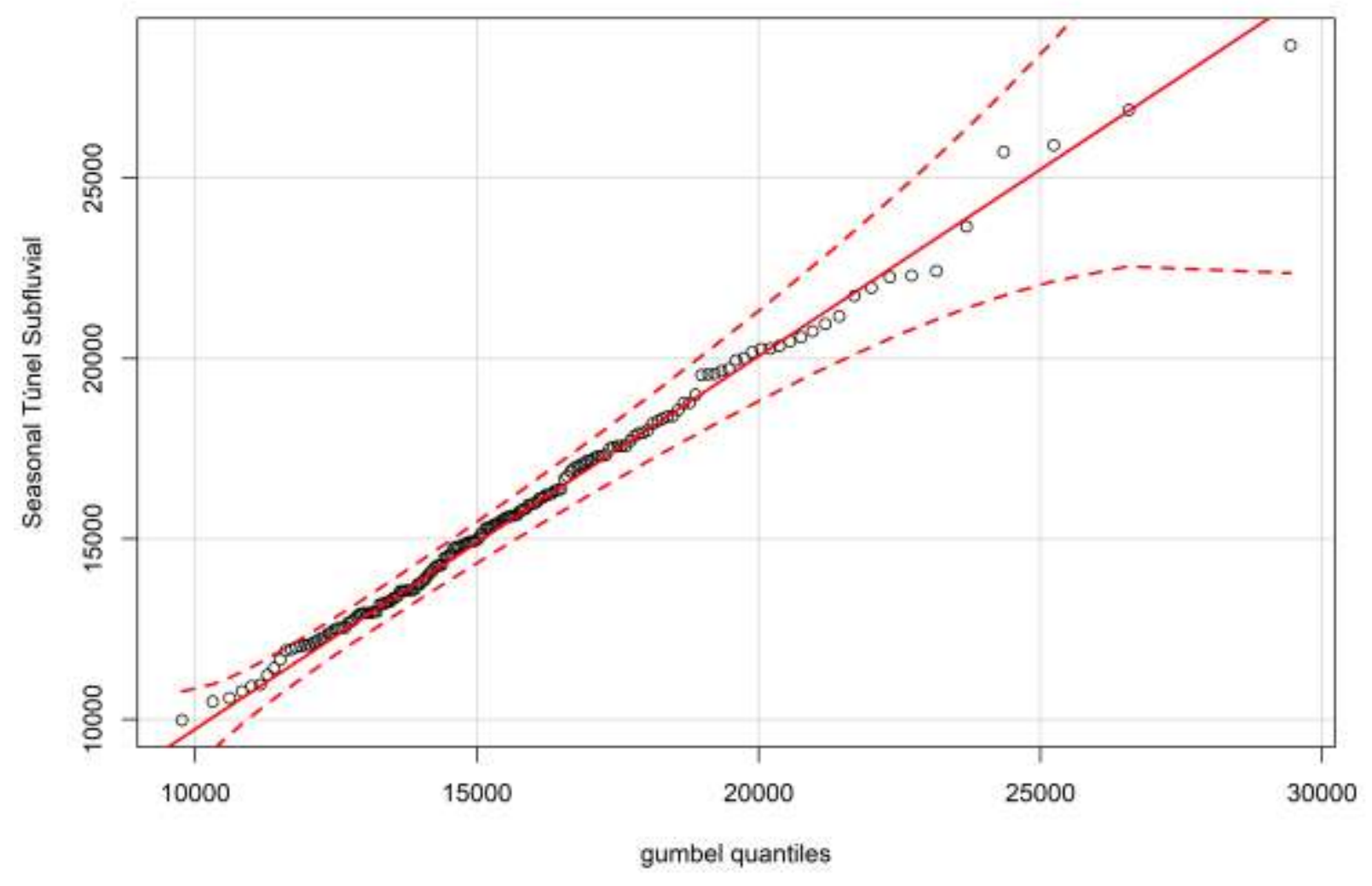


Fig 6
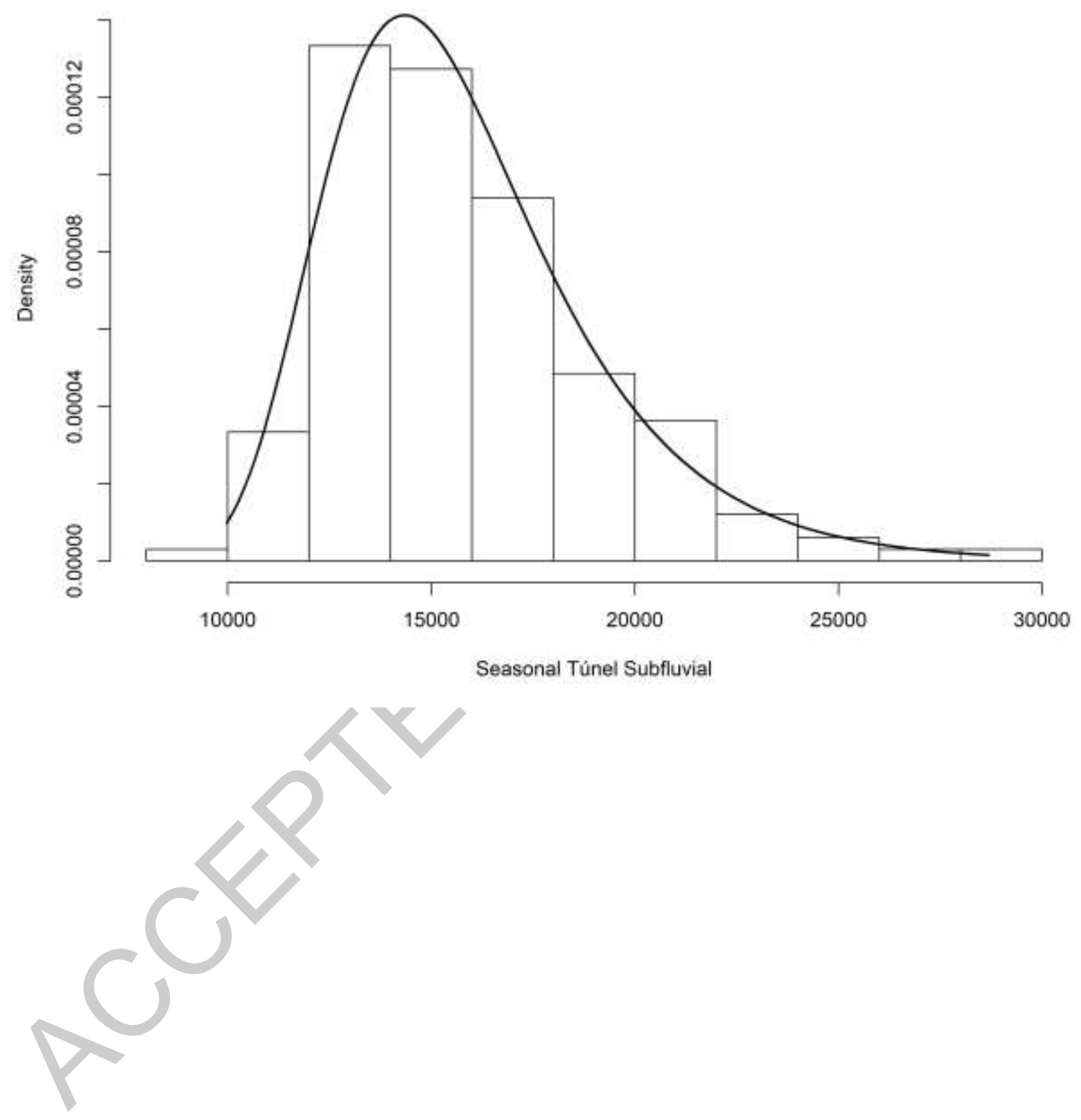
Fig 7

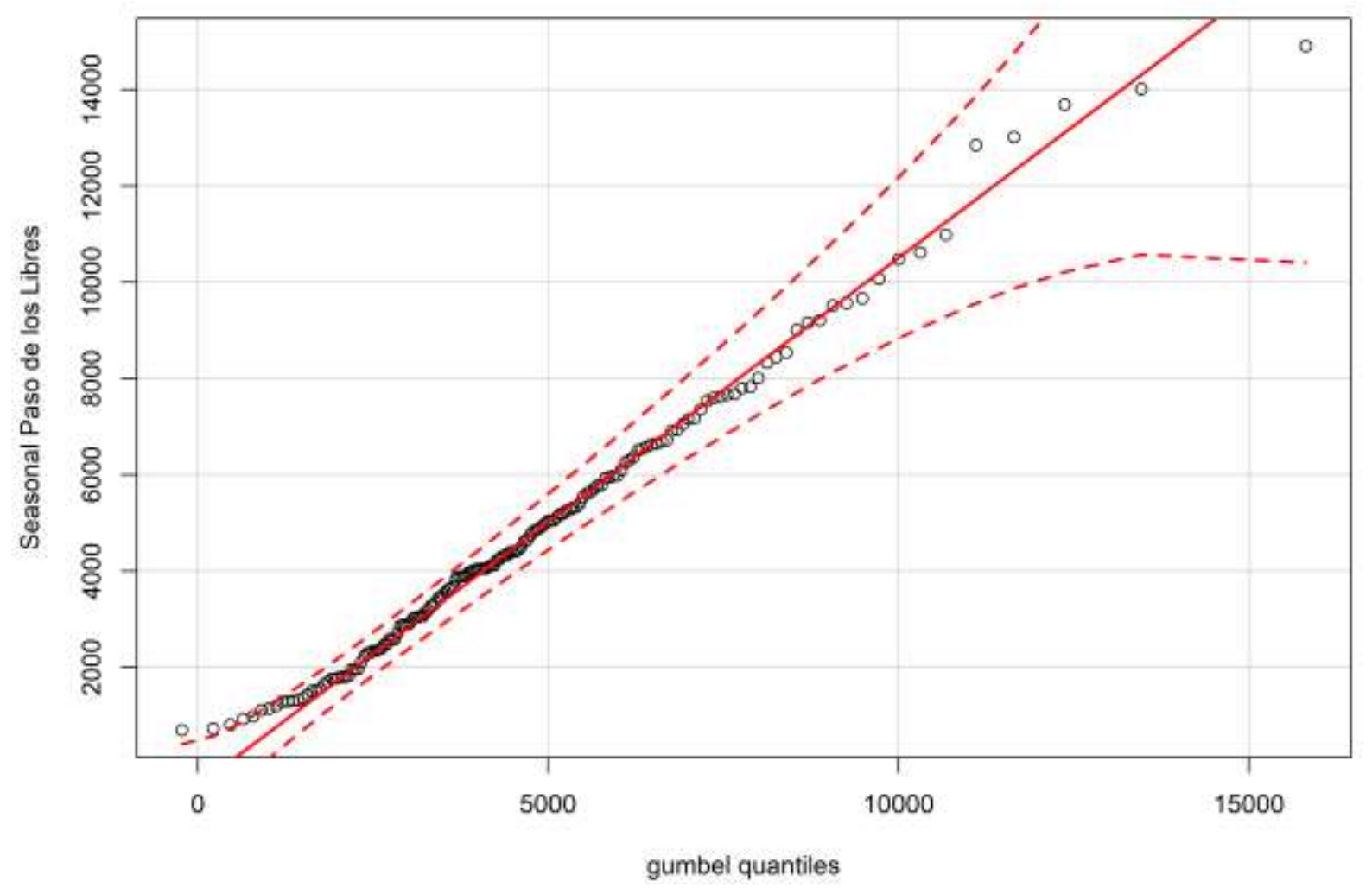


Fig 7
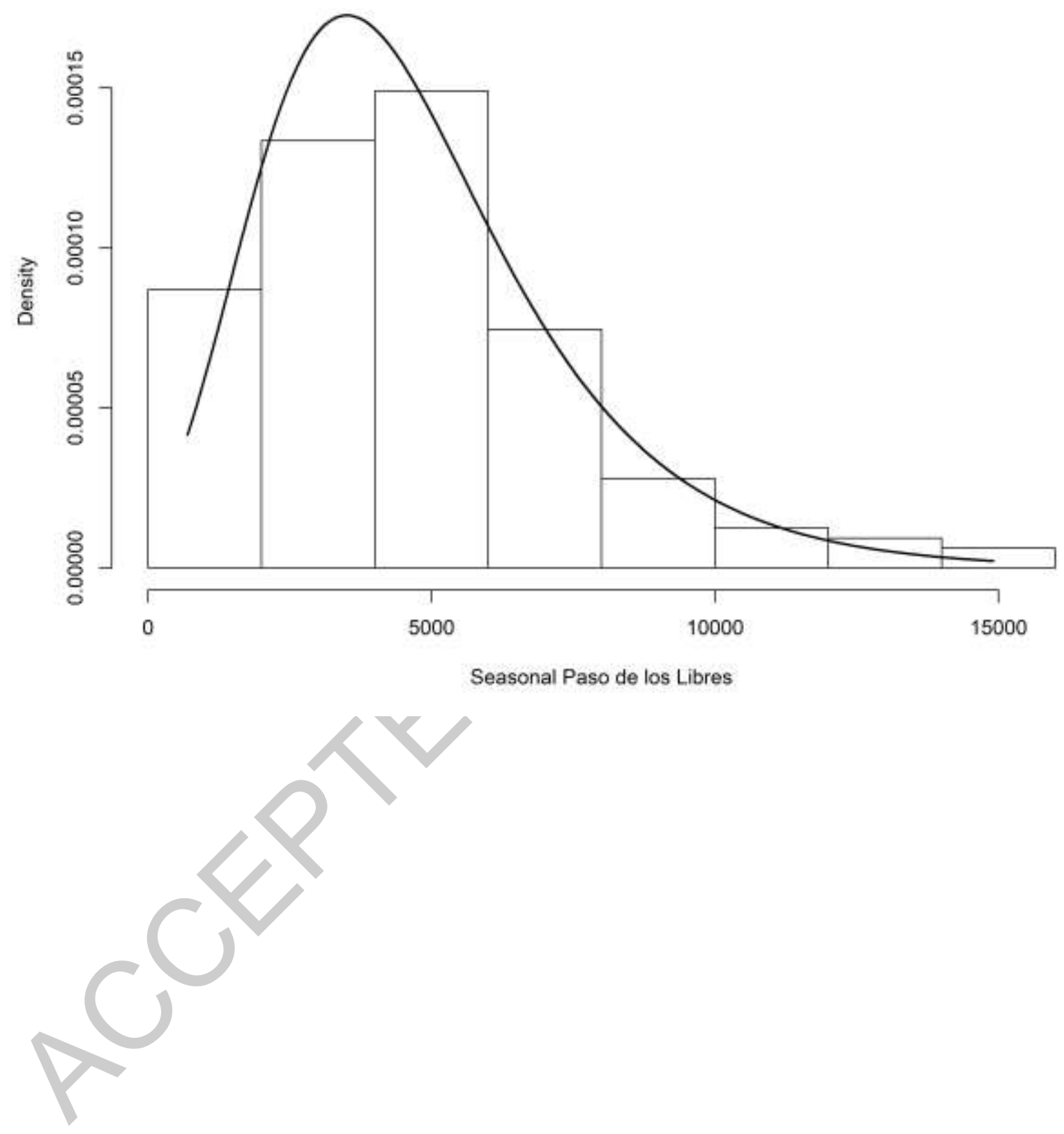
Fig 8

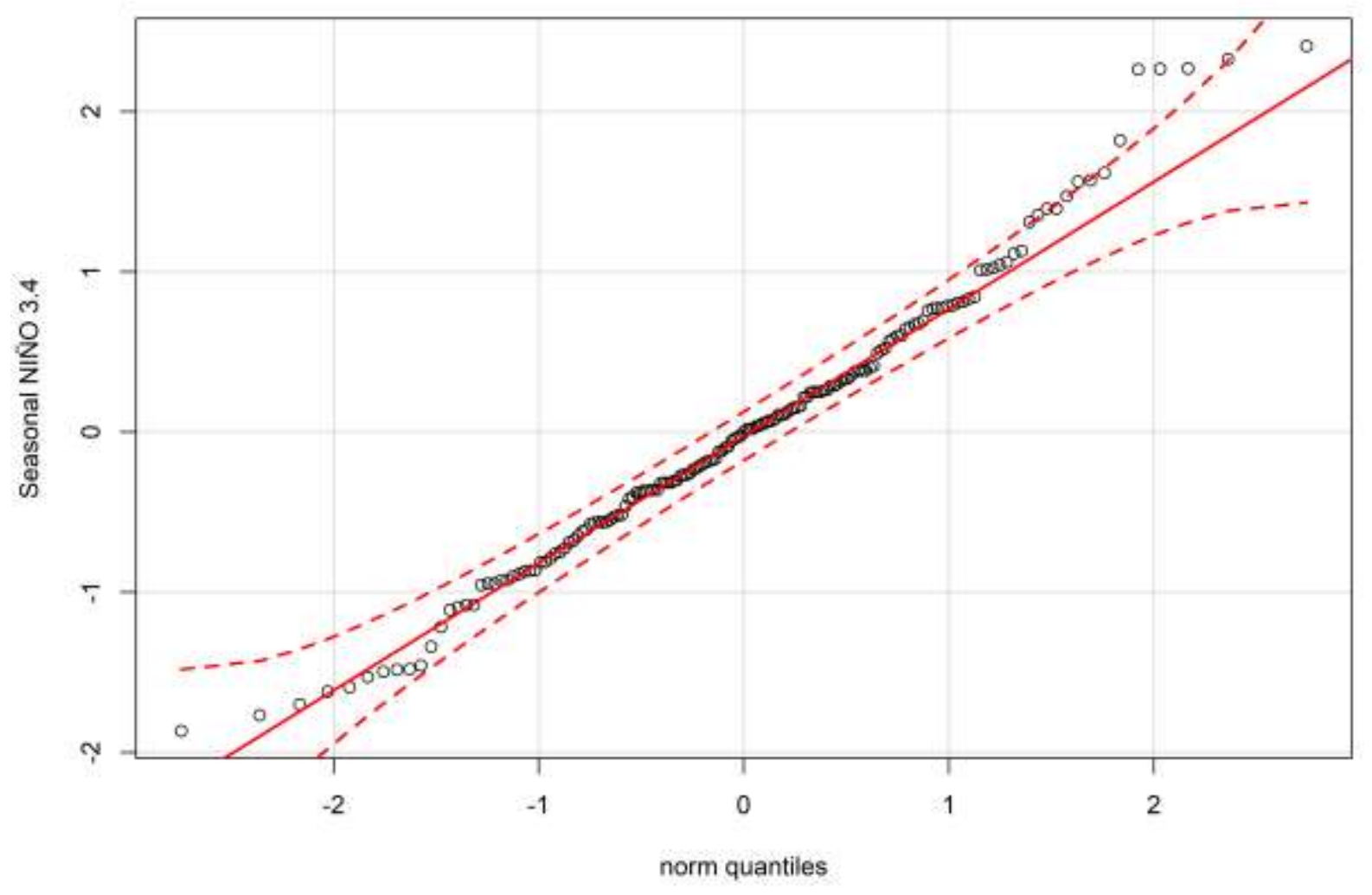


Fig 8

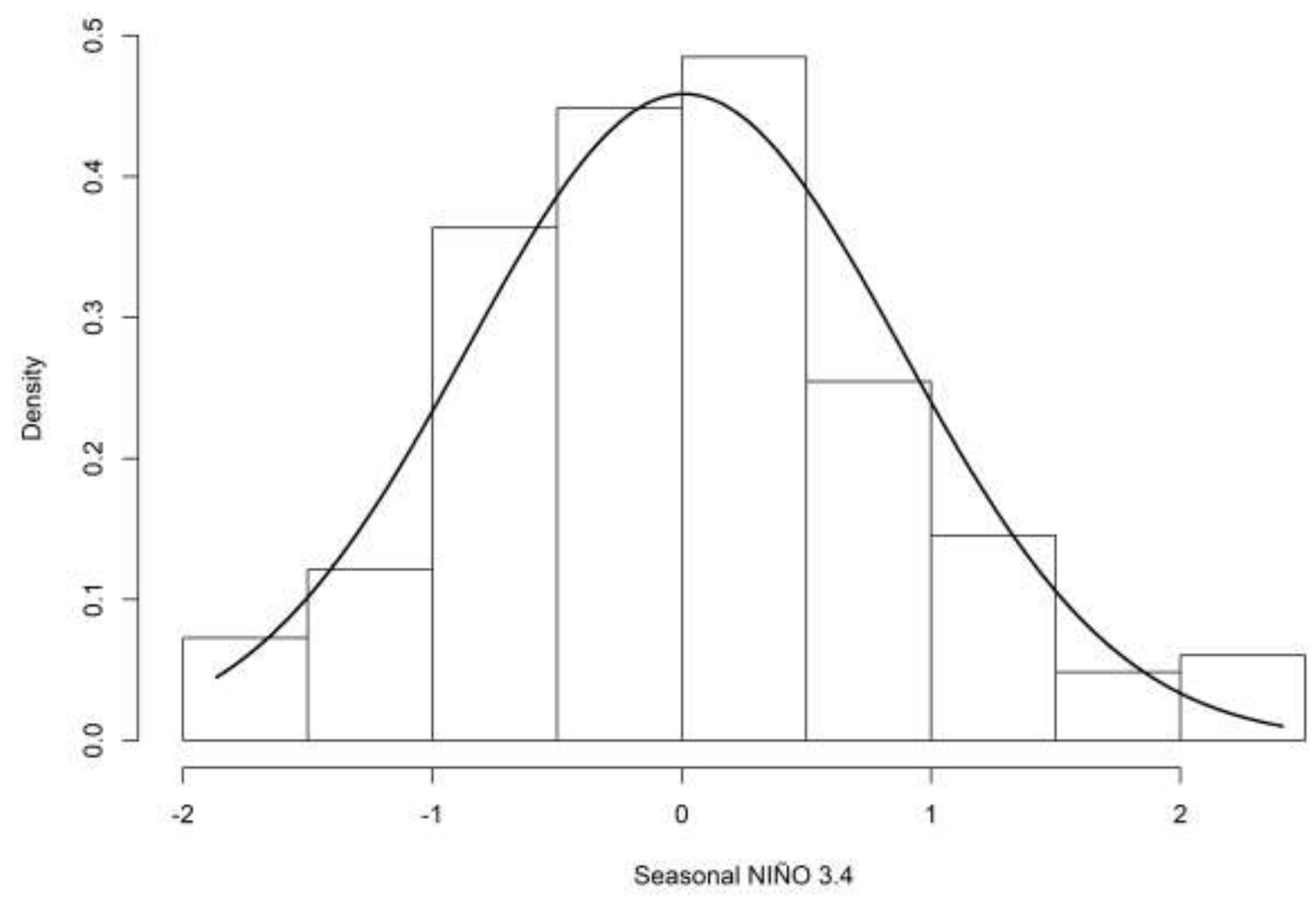


Fig 9a

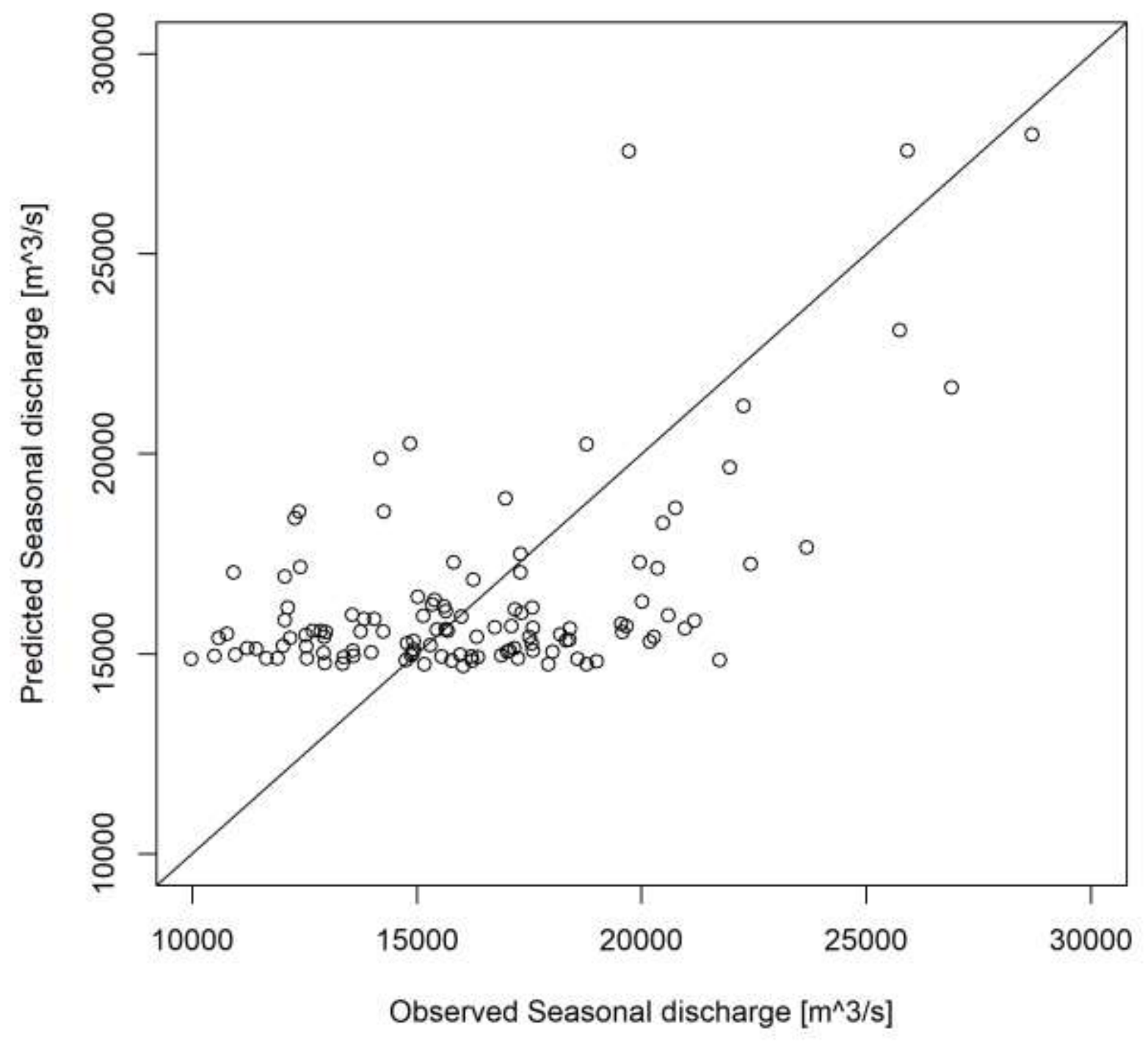


Fig $9 b$

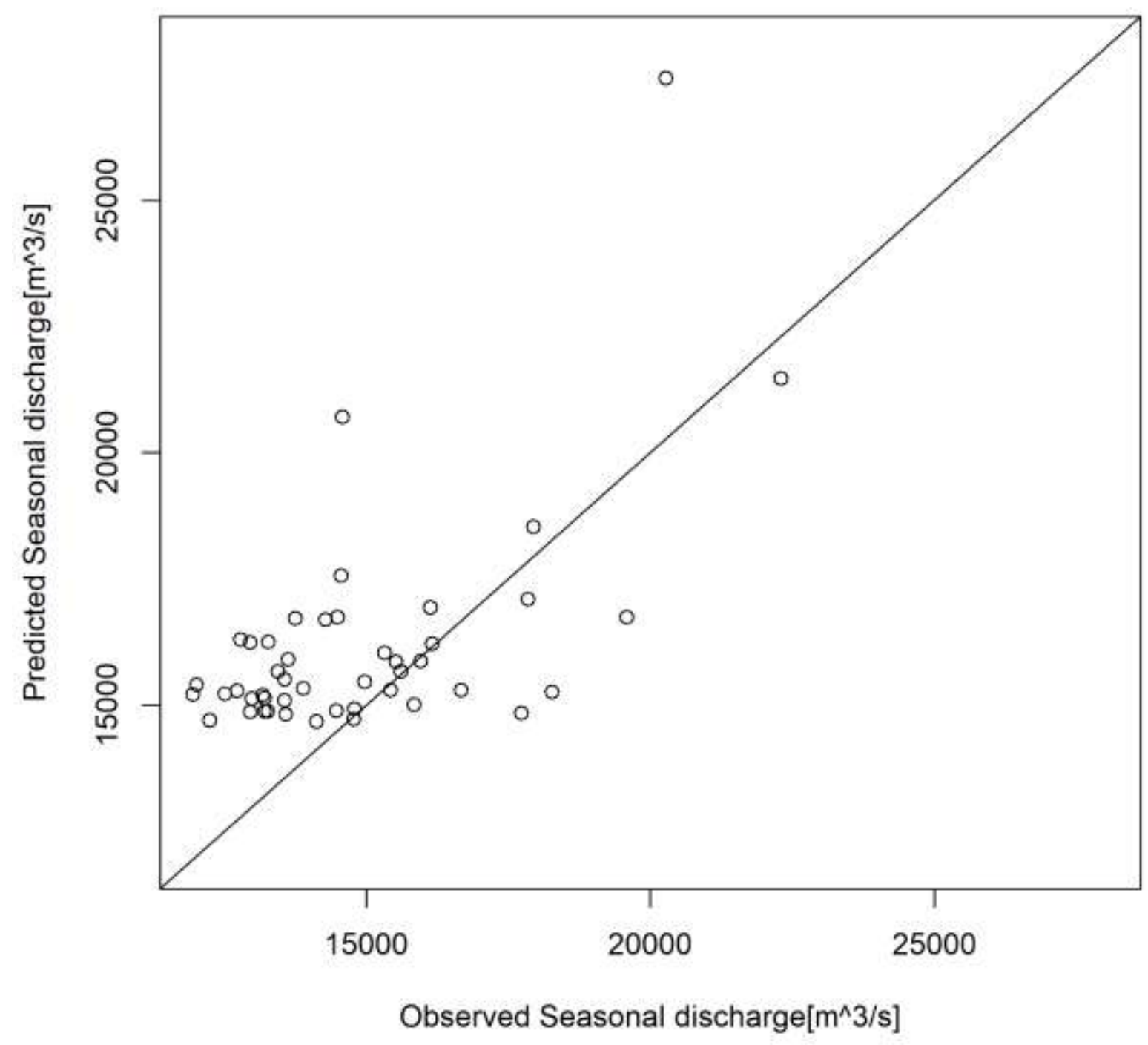


Fig 9c

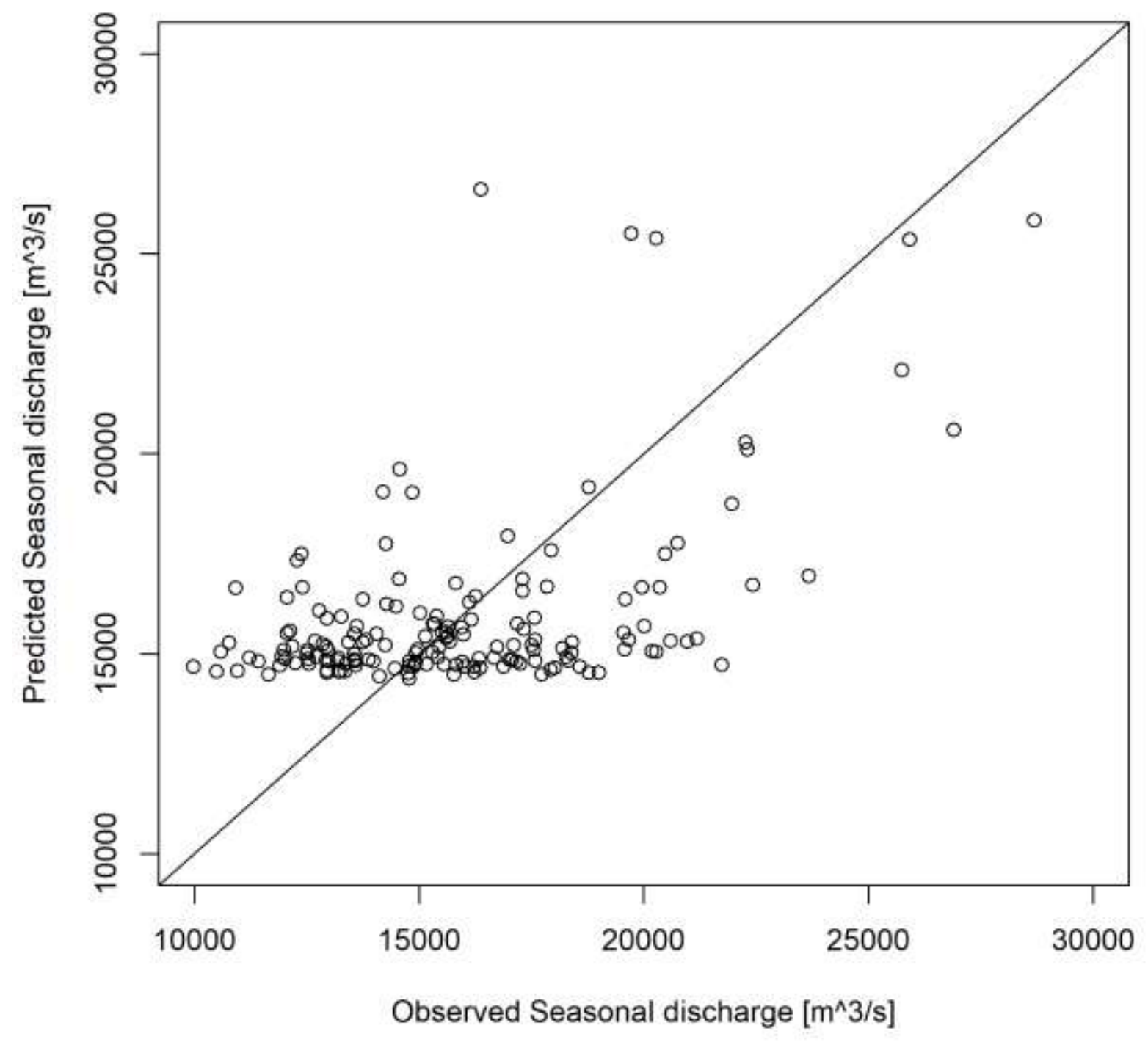


Fig 10
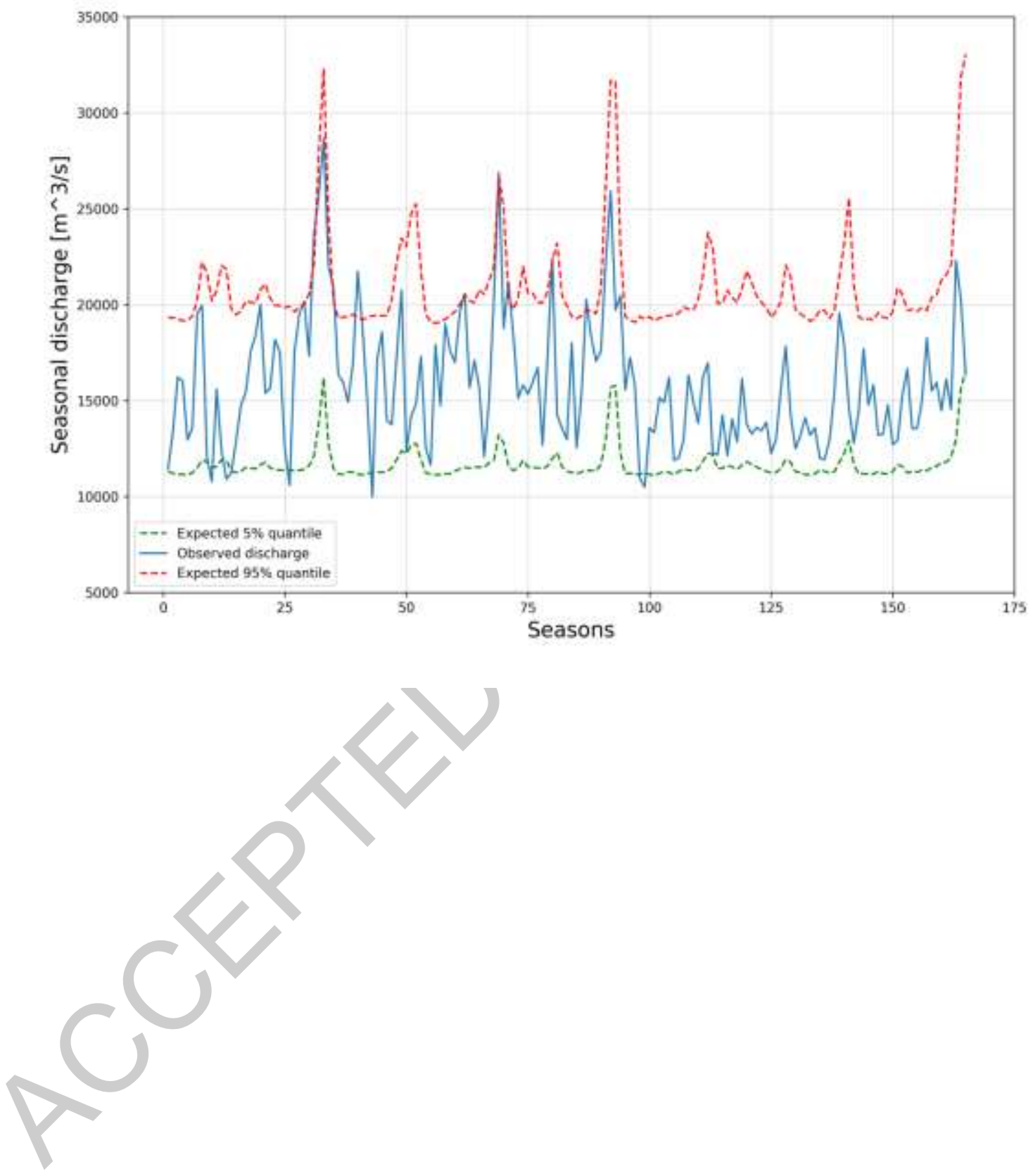
Fig 11

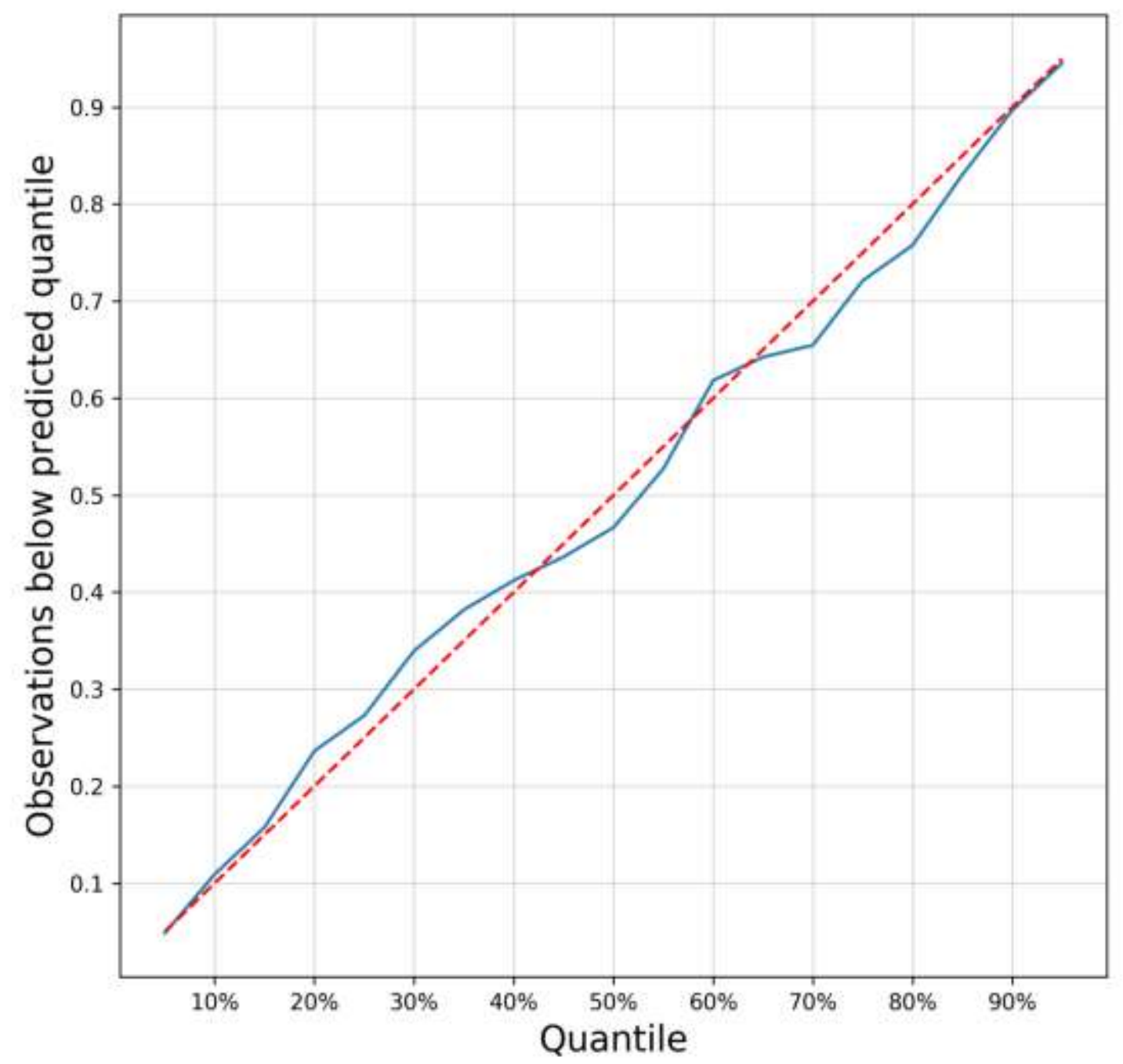


Fig 12

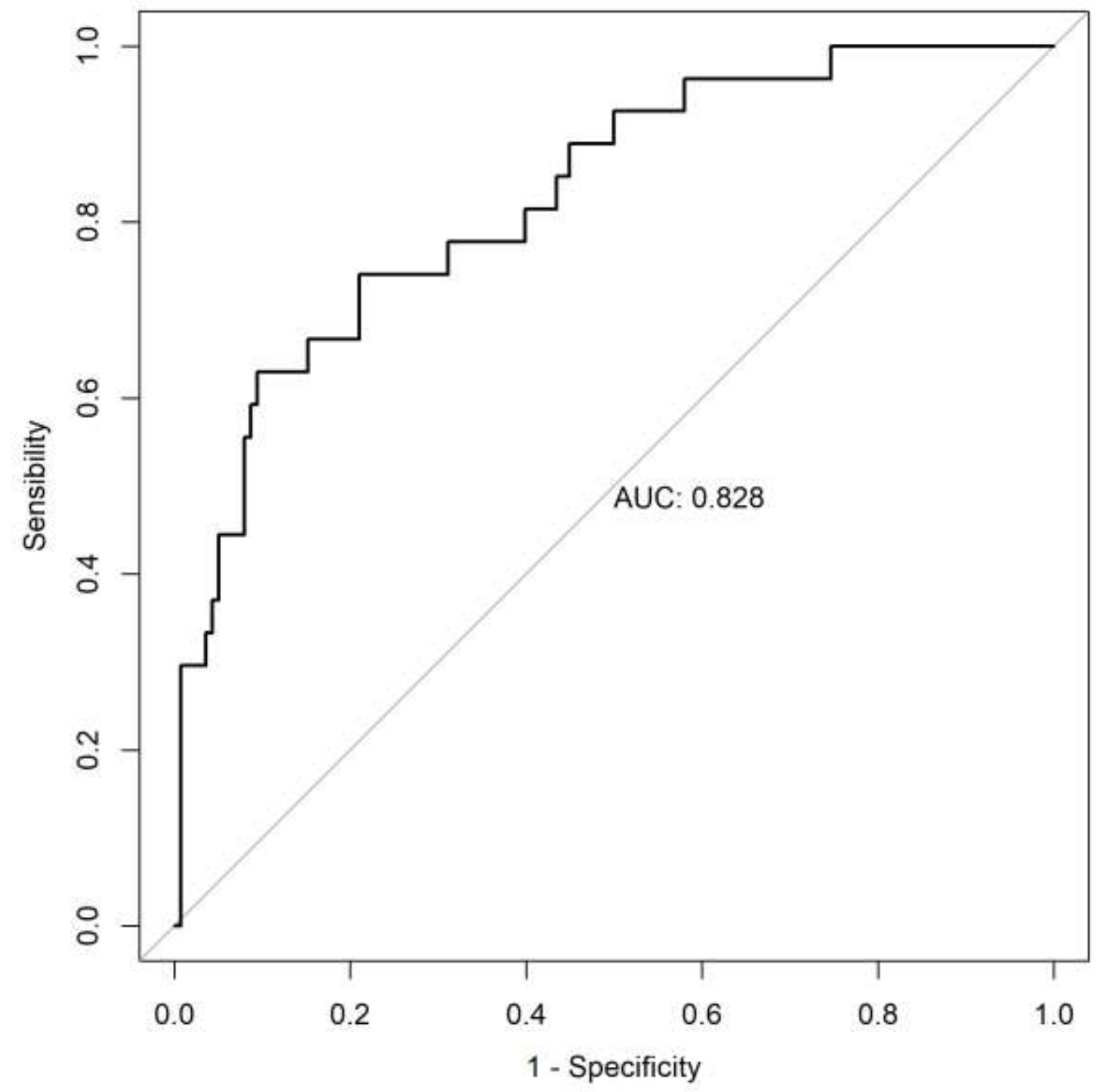


Fig 13

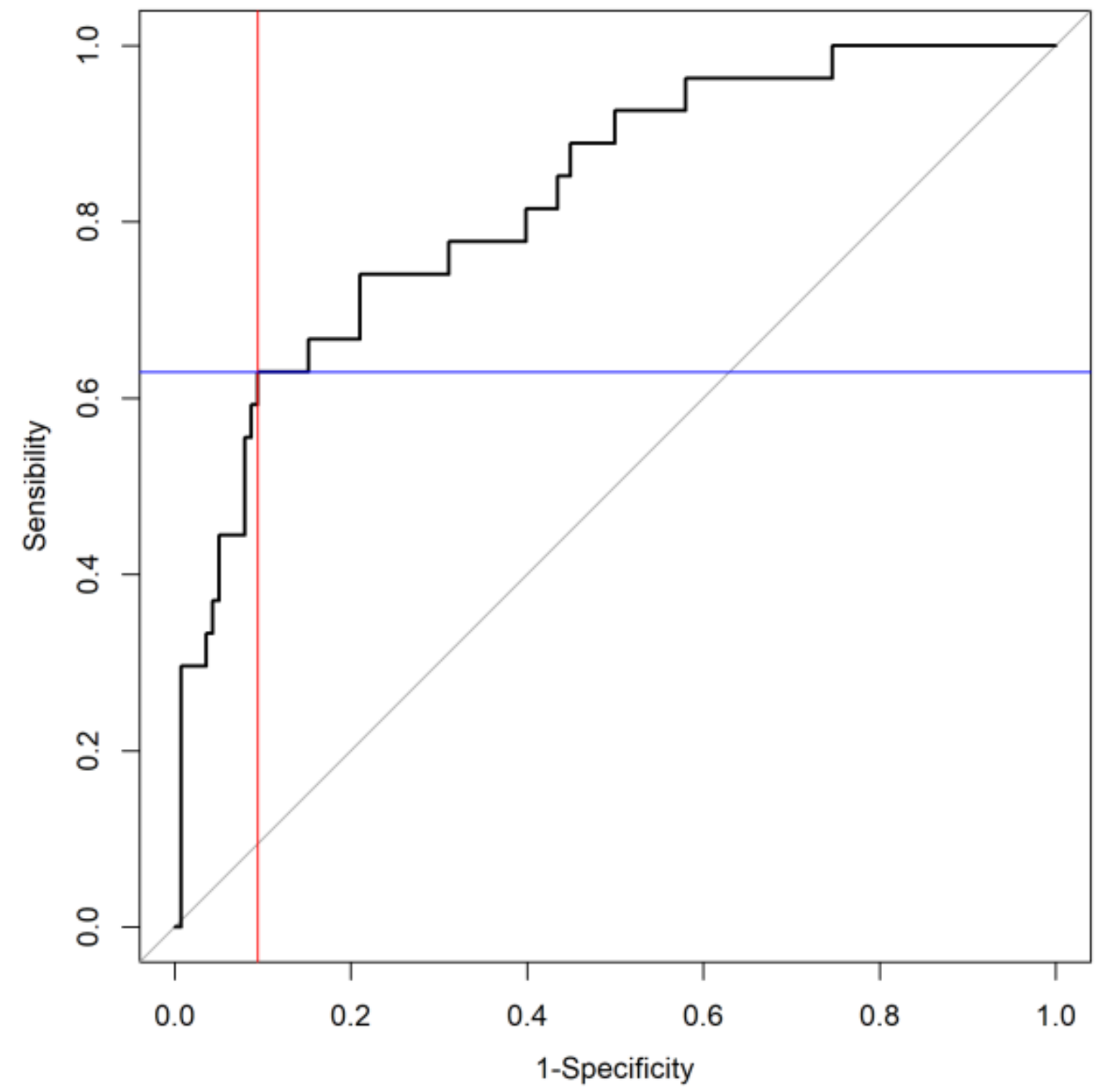


Fig 14

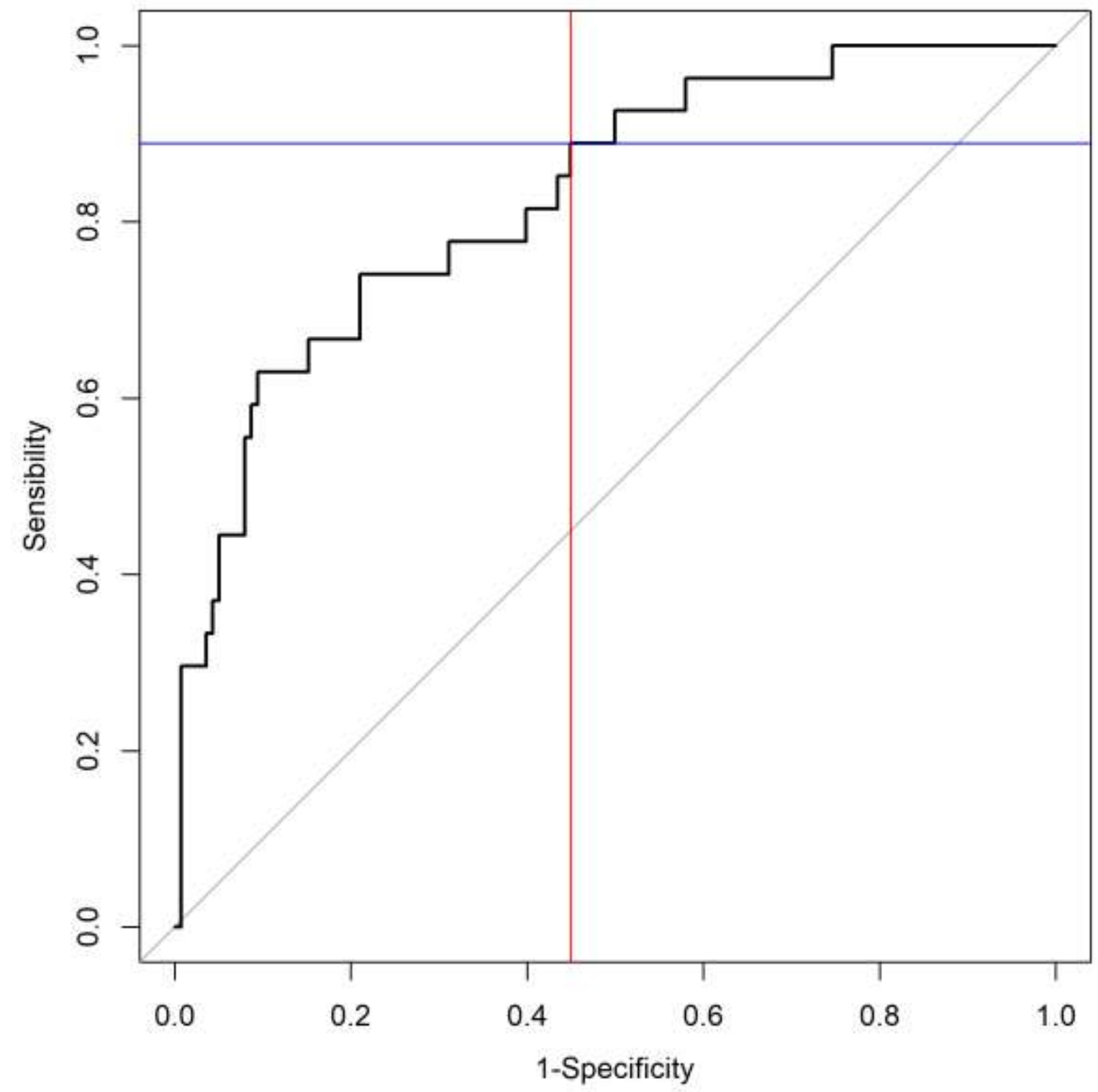


Fig 15

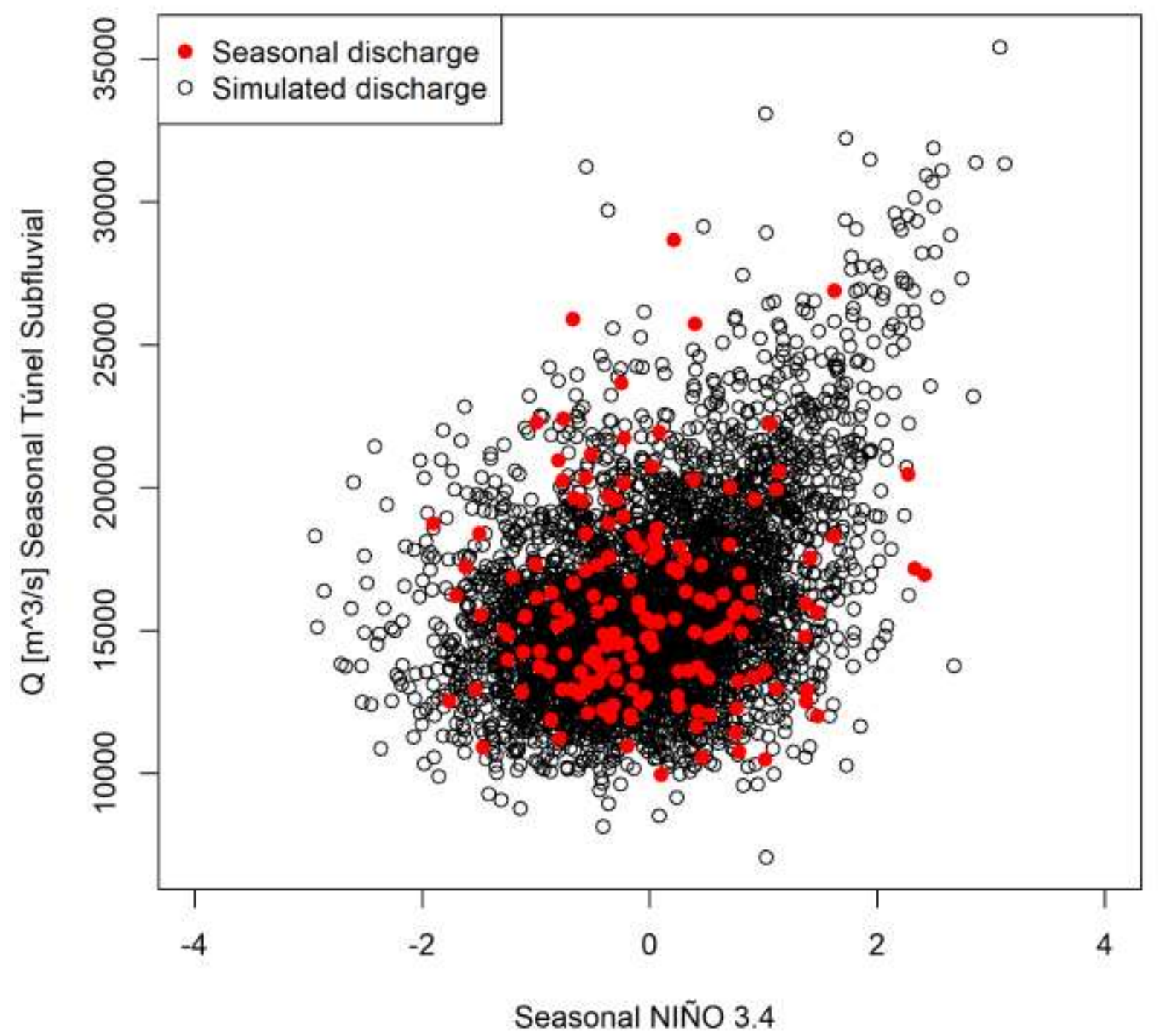


Fig 16

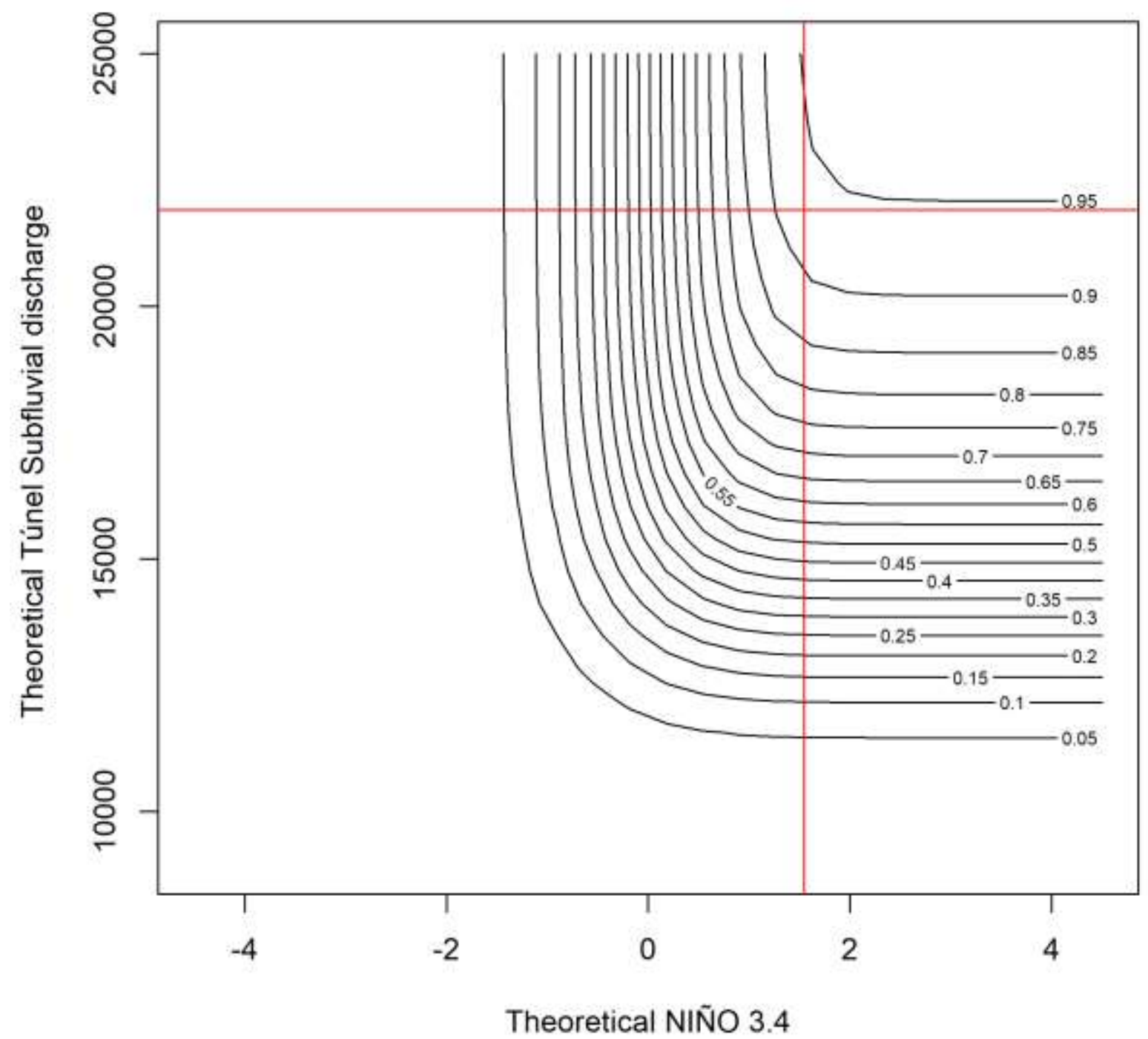


Fig 17

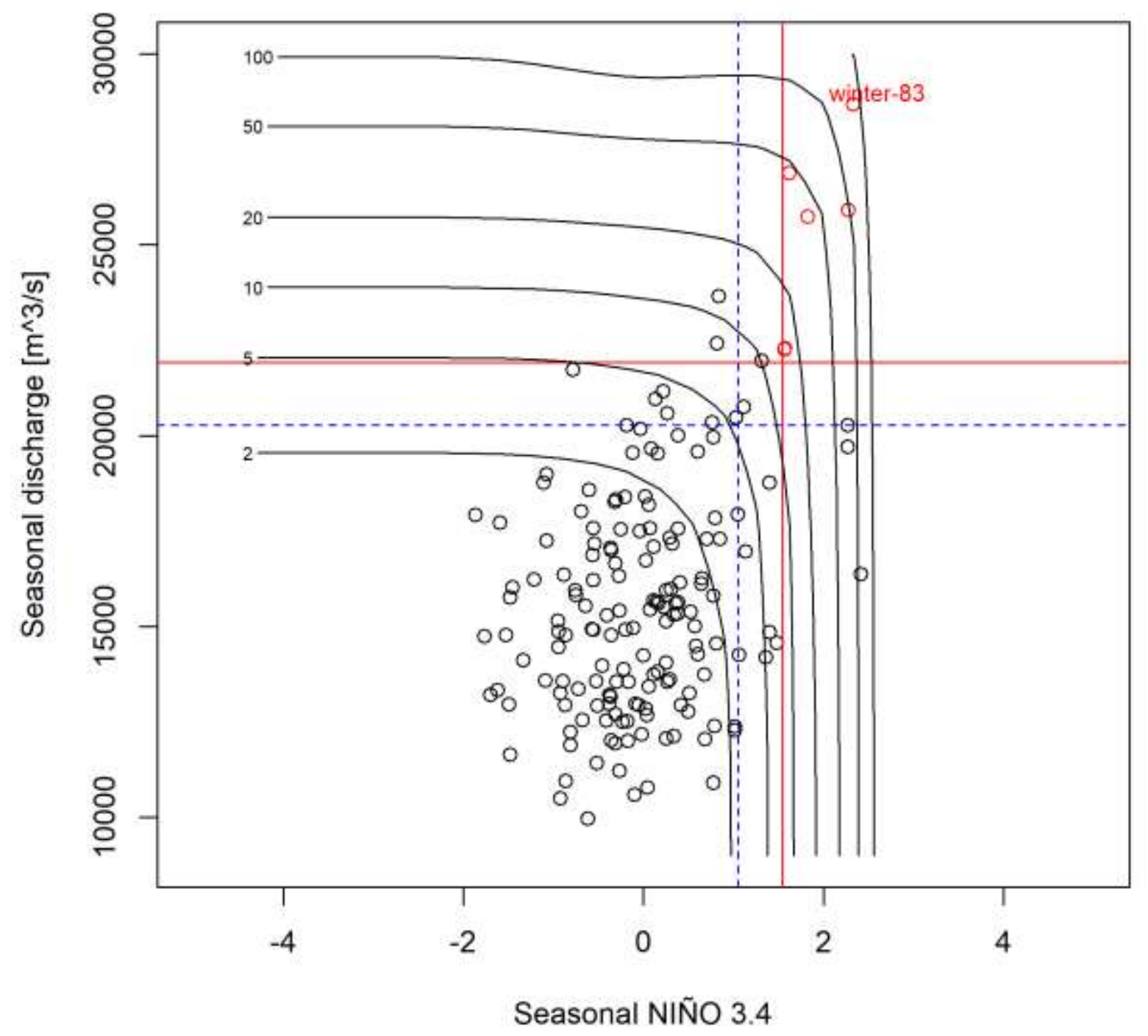


Fig 18

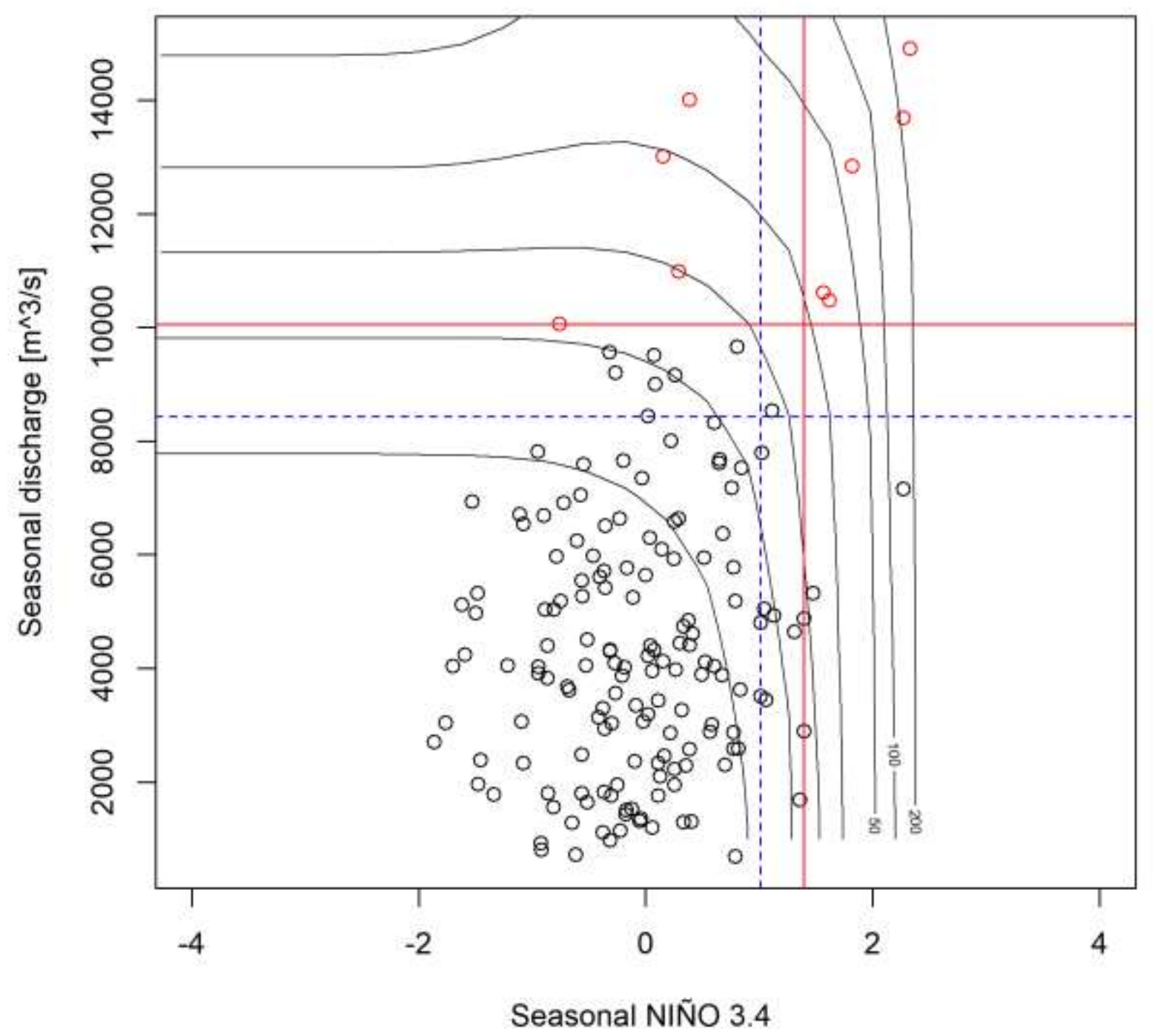

